\title{
Predicting Response of Constructed Tunnel to Adjacent Excavation with Dewatering
}

\author{
Panpan Guo $\mathbb{D}^{1},{ }^{1}$ Feifei Liu, ${ }^{2}$ Gang Lei $\mathbb{D},{ }^{1,3}$ Xian Li $\mathbb{D},{ }^{2}$ Cheng-wei Zhu $\mathbb{D}^{4},{ }^{4}$ Yixian Wang $\mathbb{D},{ }^{2,5}$ \\ Mengmeng Lu, ${ }^{6}$ Kang Cheng $\mathbb{D}^{1,7}$ and Xiaonan Gong ${ }^{1}$
}

\author{
${ }^{1}$ Research Center of Coastal and Urban Geotechnical Engineering, Zhejiang University, Hangzhou 310058, China \\ ${ }^{2}$ School of Civil Engineering, Hefei University of Technology, Hefei 230009, China \\ ${ }^{3}$ Beijing Urban Construction Design \& Development Group Company Limited, Beijing 100037, China \\ ${ }^{4}$ Institut für Geotechnik, Universität für Bodenkultur Wien, Feistmantelstrasse 4, 1180 Vienna, Austria \\ ${ }^{5}$ State Key Laboratory of Explosion Science and Technology, Beijing Institute of Technology, Beijing 100081, China \\ ${ }^{6}$ School of Mechanics and Civil Engineering, China University of Mining and Technology, Xuzhou 221116, China \\ ${ }^{7}$ China Railway 11th Bureau Group Co., Ltd., Wuhan 430061, China
}

Correspondence should be addressed to Gang Lei; 11812105@zju.edu.cn and Xian Li; 2012800022@hfut.edu.cn

Received 27 January 2021; Revised 25 February 2021; Accepted 2 March 2021; Published 18 March 2021

Academic Editor: Yu Wang

Copyright (C) 2021 Panpan Guo et al. This is an open access article distributed under the Creative Commons Attribution License, which permits unrestricted use, distribution, and reproduction in any medium, provided the original work is properly cited.

\begin{abstract}
This paper proposes a new method for predicting the displacement and internal force of constructed tunnels induced by adjacent excavation with dewatering. In this method, the total excavation-induced additional stress on the constructed tunnel is derived by superposing the additional stresses induced by excavation unloading and dewatering effects. The additional stress induced by unloading effect is calculated using Mindlin's solution. The additional stress induced by dewatering effect is calculated using the principle of effective stress and the Dupuit precipitation funnel curve. With the beam on elastic foundation method, the total additional stress is then used for calculating the tunnel displacement and internal force caused by adjacent excavation with dewatering. Based on three well-documented case histories, the performance of the proposed method is verified. Moreover, a parametric analysis is also performed to capture the effects of excavation depth, tunnel-to-excavation distance, initial water level, excavation plan view size, and specific yield on the responses of the constructed tunnels. The results indicate that the effect of excavation depth on the tunnel maximum vertical displacement, maximum bending moment, and maximum shear force is more significant at an excavation depth greater than the cover depth of the constructed tunnel. The tunnel maximum vertical displacement, maximum bending moment, and maximum shear force decrease nonlinearly with an increase in the tunnel-toexcavation distance and the initial water level. Among the investigated parameters, the excavation dimension in the tunnel longitudinal direction affects most the tunnel responses. The effect of specific yield on the tunnel displacement and internal force induced by adjacent excavation with dewatering becomes more obvious as increasing the initial water level and excavation depth.
\end{abstract}

\section{Introduction}

The rapid development of urban rail traffic provides convenience of getting around for people. The development advantage along an urban rail traffic line has been stimulating the construction of high-rise buildings adjacent to the urban rail traffic line. Therefore, it is not rare to find an excavation that is adjacent to preexisting subway tunnels, piles, pipelines, or other shallowly buried facilities [1-5]. Inevitably, the adja- cent excavation has an adverse effect on the constructed structures or facilities, and many studies have focused on this issue in recent decades [6-8]. It has been found that the excavation-induced redistribution of ground stress can lead to the generation of additional stress and deformation in the tunnel structure. If the induced tunnel deformation is excessive, the safe operation of the subway or other facilities will be affected [9-12]. As a result, an investigation into the excavation-induced internal force and deformation 
characteristics of a constructed subway tunnel has great significance to the safe operation of the subway tunnel [13-15].

Many analysis methods for excavation-induced internal force and deformation in a subway tunnel have been proposed, which can be classified into the numerical analysis method [16-19], field monitoring method [20-23], and theoretical analysis method [24-26]. The numerical analysis method can simulate the complex process of excavation and is therefore a favored choice for engineers and researchers. However, this method suffers from several disadvantages such as cumbersome modelling, timeconsuming computation, large discrepancy between the computed results using different numerical analysis software, and low reliability of the computed results. The field monitoring method can directly obtain the excavation-induced deformation behavior of the constructed tunnel during the whole excavation phase. However, this method is susceptible to the workers' operating skill and the quality of monitoring equipment. Moreover, the field monitoring method corresponds to only a specific engineering project and does not involve a discussion of the deformational mechanism and therefore has a limited guiding significance for the excavations in other areas.

The theoretical analysis method for excavation-induced internal force and deformation characteristics in a subway tunnel has been extensively investigated by many scholars. At the present time, the most common-adopted theoretical analysis method is the two-stage method [27, 28]. This method divides the considered problem into two separate stages: the excavation unloading stage and the tunnel responding stage. Depending on the concept of predicting the excavation-induced response of the constructed tunnel, the method for calculating the excavation-induced internal force in the constructed tunnel can be categorized into the additional load method and the additional displacement method [29-31]. The additional load method is performed in two steps. First, apply the excavation-induced additional stress in the tunnel position calculated by Mindlin's solution to the constructed subway tunnel. Second, calculate the internal force and deformation in the constructed tunnel under the effect of the applied excavation-induced additional stress, by adopting the beam on elastic foundation theory $[32,33]$. The additional displacement method is also performed in two steps. First, calculate the excavation-induced ground displacement in the tunnel position by using Peck's formula [34]. Second, impose the calculated displacement in the first step on the constructed tunnel to predict the internal force and deformation in the constructed tunnel $[35,36]$.

The change of the initial stress field in the ground induced by an excavation is a rather complex phenomenon. This phenomenon is associated with not only the excavation unloading effect but also the excavation dewatering effect. Previous research has indicated that excavation dewatering affects significantly the internal force and deformation characteristics of the constructed facilities adjacent to the excavation [37-40]. Based on the effective stress principle, Ou et al. [41] proposed an analytical method for predicting the influence of excavation with dewatering on the response of the constructed tunnel underlying the excavation. This method takes account of the excavation dewatering effect but is not applicable to the condition where the excavation is adjacent laterally to the constructed tunnel. In addition, based on Darcy's law and the Dupuit approximation, Anderson [42] derived a formula describing the steady flow of groundwater and determined the precipitation funnel curve using the groundwater surfaces on the external and internal boundaries.

In this paper, the excavation unloading effect and the excavation dewatering effect are modelled separately. Mindlin's solution is used to calculate the additional stress in the constructed tunnel induced by the excavation unloading effect. Based on the Dupuit precipitation funnel curve, the effective stress in the constructed tunnel induced by the excavation dewatering effect is obtained. The additional stress and the effective stress obtained above are then superimposed to derive the total additional stress in the constructed tunnel. After this, the additional load method is adopted to predict the internal force and displacement characteristics for the constructed tunnel adjacent to an excavation with dewatering. The innovation of this study lies in that the calculation of the excavation-induced additional stress takes account of not only the excavation unloading and dewatering effects but also the entire region subjected to the influence of dewatering by introducing the Dupuit precipitation funnel curve.

\section{Total Additional Stress Induced by Excavation with Dewatering}

In calculating the additional stress in the constructed tunnel induced by excavation with dewatering, the time effect involved in the excavation and dewatering process is not taken into account, and only the initial state and the final state of the excavation with dewatering have been considered. In general, the additional stress in the constructed tunnel induced by excavation with dewatering is composed of two parts: one is the effective stress effect induced by dewatering, and the other is the unloading effect induced by excavation.

2.1. Additional Stress Induced by Dewatering. It is assumed that the phreatic line induced by dewatering conforms to the Dupuit approximation [42]. In detail, the assumptions are as follows: (1) the aquifer is homogeneous, isotropic, isopachous, and horizontal; (2) the flow of the groundwater is laminar and stable and conforms to Darcy's law; (3) the static water level is horizontal; and (4) the contour of recharge of the pumping well is of fixed water level and is cylindrical in shape. A schematic of the dewatering during an excavation is presented in Figure 1.

The adopted water level lowing curve has the form

$$
y^{2}=h^{\prime 2}+\left(H^{2}-h^{\prime 2}\right) \frac{\ln x-\ln r}{\ln R-\ln r}
$$

where $y=$ elevation of the phreatic line after dewatering $(\mathrm{m})$, $h^{\prime}=$ distance between the water level of the dewatering well and the impermeable layer $(\mathrm{m}), H=$ elevation of the initial water level $(\mathrm{m}), r=$ radius of the dewatering well $(\mathrm{m}), R=$ radius of influence of dewatering $(\mathrm{m}), x=$ horizontal 


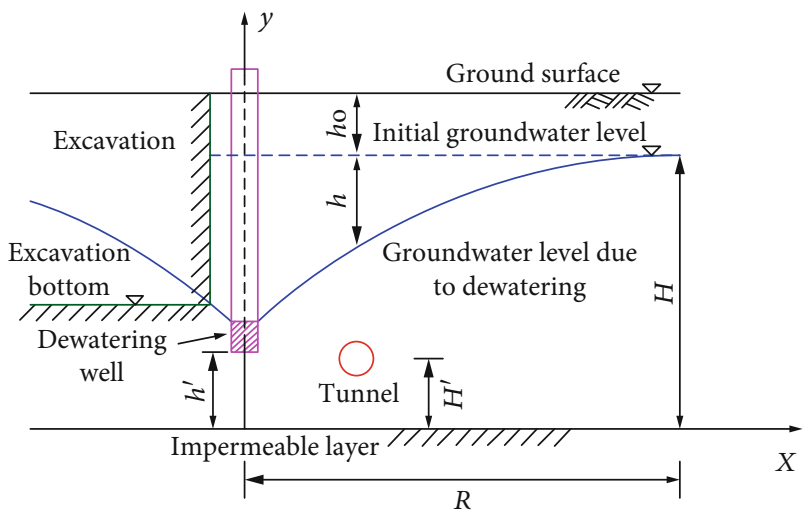

Figure 1: Schematic of dewatering during excavation.

distance to the axis of the dewatering well (m), and $H^{\prime}=$ distance between tunnel axis and impermeable layer.

The radius of influence of dewatering can be calculated using an empirical equation

$$
R=2 s \sqrt{H K}
$$

where $s=$ dewatering depth of the dewatering well $(\mathrm{m})$ and $K=$ permeability coefficient of the ground $(\mathrm{m} / \mathrm{d})$.

The change of the water level above the constructed tunnel can thus be estimated using Equations (1) and (2). The vertical additional stress applied on the constructed tunnel is calculated using the effective stress principle. Before dewatering, the constructed tunnel is subjected to earth pressure and pore water pressure, and the effective stress is calculated by

$$
\sigma=h_{0} \gamma_{0}+(H-y)\left(\gamma_{\text {sat }}-\gamma_{\mathrm{w}}\right)
$$

where $h_{0}=$ distance between ground surface and initial water level $(\mathrm{m}), \quad \gamma_{0}=$ dry unit weight of soil $\left(\mathrm{kN} / \mathrm{m}^{3}\right), \quad \gamma_{\mathrm{sat}}=$ saturated unit weight $\left(\mathrm{kN} / \mathrm{m}^{3}\right)$, and $\gamma_{\mathrm{w}}=$ unit weight of water $\left(\mathrm{kN} / \mathrm{m}^{3}\right)$.

After dewatering, the effective stress applied to the constructed tunnel is given by

$$
\sigma^{\prime}=h_{0} \gamma_{0}+(H-y)\left(\gamma_{\text {sat }}-(1-\mu) \gamma_{\mathrm{w}}\right)
$$

where $\mu=$ specific yield. The magnitude of $\mu$ is associated with soil properties including the mineral composition, particle size, grain grading, degree of sorting, and void ratio. The mineral composition affects the specific yield by the adsorption force on the hydrone. A summary of the empirical values of the specific yield for various types of soils is presented in Table 1.

The dewatering-induced change of the vertical effective stress applied on the constructed tunnel is calculated by

$$
\sigma_{w}^{v}=\sigma^{\prime}-\sigma=\mu(H-y) \gamma_{\mathrm{w}}=\mu h \gamma_{\mathrm{w}} .
$$

2.2. Additional Stress Induced by Unloading. The calculation of the additional stress in the constructed tunnel induced by excavation unloading effect is generally based on Mind-
TABLE 1: Empirical values of the specific yield for various types of soils.

\begin{tabular}{lc}
\hline Soil type & Specific yield \\
\hline Clay & $0.02-0.035$ \\
Loam & $0.03-0.045$ \\
Sandy loam & $0.035-0.06$ \\
Loess-like loam & $0.02-0.05$ \\
Loess-like sandy loam & $0.03-0.06$ \\
Silty sand & $0.06-0.08$ \\
Silty fine sand & $0.07-0.01$ \\
Fine sand & $0.08-0.11$ \\
Medium-fine sand & $0.085-0.12$ \\
Medium sand & $0.09-0.13$ \\
Medium-coarse sand & $0.10-0.15$ \\
Coarse sand & $0.11-0.15$ \\
Clay cemented sandstone & $0.02-0.03$ \\
Fractured limestone & $0.008-0.10$ \\
\hline
\end{tabular}

lin's solution [43]. A schematic of the calculation model for the additional stress induced by unloading is presented in Figure 2. The assumptions involved in Mindlin's solution are as follows: (1) the ground is a homogeneous, elastic half-space, (2) the time and space effects involved in the excavation are overlooked, and (3) the influence of the constructed tunnel on the excavation unloading stress is not taken into account.

According to Mindlin's solution, under the effect of unit force $\sigma d \xi d \eta$ applied at the point $(\xi, \eta)$ at the excavation bottom, the vertical and horizontal additional stresses at the point $(x, y, z)$ on the tunnel axis are calculated by

$$
\begin{aligned}
\sigma_{d}^{v}= & -\frac{\gamma d}{8 \pi(1-v)}\left[\frac{(1-2 v)(z-d)}{R_{1}^{3}}-\frac{(1-2 v)(z-d)}{R_{2}^{3}}\right. \\
& +\frac{3(z-d)^{3}}{R_{1}^{5}}+\frac{3(3-4 v) z(z+d)^{2}-3 d(z+d)(5 z-d)}{R_{2}^{5}} \\
& \left.+\frac{30 z d(\mathrm{z}+d)^{3}}{R_{2}^{7}}\right]
\end{aligned}
$$

$$
\begin{aligned}
\sigma_{d}^{h}= & -\frac{\gamma d}{8 \pi(1-v)}\left[-\frac{(1-2 v)(z-d)}{R_{1}^{3}}+\frac{3(x-\xi)^{2}(z-d)}{R_{1}^{5}}\right. \\
& -\frac{(1-2 v)[3(z-d)-4 v(z+d)]}{R_{2}^{3}} \\
& +\frac{\left\{3(3-4 v)(x-\xi)^{2}(z-d)-6 d(z+d)[(1-2 v) z-2 v d]\right\}}{R_{2}^{5}} \\
& +\frac{4(1-v)(1-2 v)}{R_{2}\left(R_{2}+z+d\right)}\left[1-\frac{(x-\xi)^{2}}{R_{2}\left(R_{2}+z+d\right)}-\frac{(x-\xi)}{R_{2}^{2}}\right] \\
& \left.+\frac{30(x-\xi)^{2} z d(z+d)}{R_{2}^{7}}\right],
\end{aligned}
$$



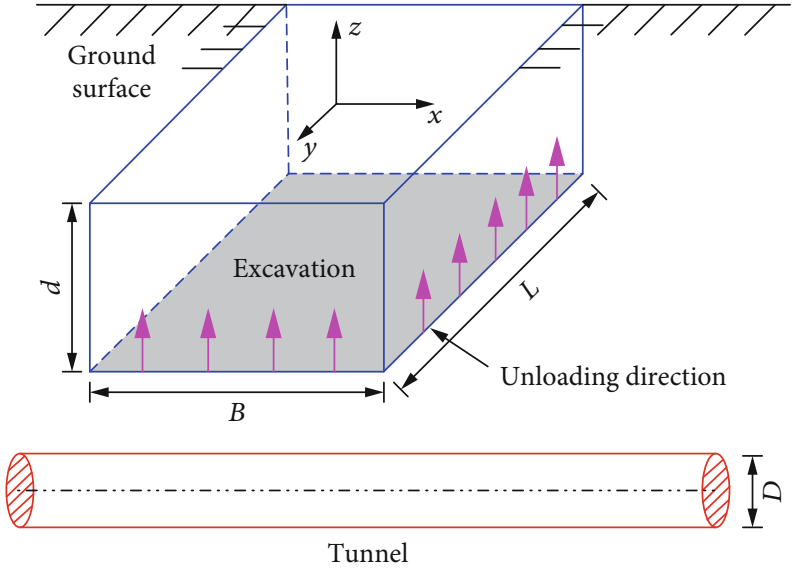

FIgURE 2: Schematic of the calculation model for additional stress induced by excavation unloading.

$$
\begin{gathered}
R_{1}=\sqrt{(x-\xi)^{2}+(y-\eta)^{2}+(z-d)^{2}}, \\
R_{2}=\sqrt{(x-\xi)^{2}+(y-\eta)^{2}+(z+d)^{2}} .
\end{gathered}
$$

Similarly, under the effect of a unit force $K_{0} \gamma \tau d \eta d \tau$ applied at the point $(\eta, \tau)$ on the vertical side of the excavation, the vertical and horizontal additional stresses at the point $(x, y, z)$ on the tunnel axis are calculated by

$$
\begin{aligned}
\sigma_{c}^{v}= & -\frac{K_{0} \gamma \tau S}{8 \pi(1-v)}\left[\frac{-(1-2 v)}{R_{3}^{3}}+\frac{3(z-\tau)^{2}}{R_{3}^{5}}+\frac{(1-2 v)}{R_{4}^{3}}\right. \\
& +\frac{3(3-4 v)(z+\tau)^{2}}{R_{4}^{5}} \\
& \left.+\frac{-6 \tau}{R_{4}^{5}}\left(\tau+(1-2 v)(z+\tau)+\frac{5 z(z+\tau)^{2}}{R_{4}^{2}}\right)\right], \\
\sigma_{c}^{h}=- & \frac{K_{0} \gamma \tau S}{8 \pi(1-v)}\left[\frac{(1-2 v)}{R_{3}^{3}}+\frac{3 S^{2}}{R_{3}^{5}}+\frac{(1-2 v)(5-4 v)}{R_{4}^{3}}\right. \\
+ & \frac{3(3-4 v) S^{2}}{R_{4}^{5}}+\frac{4(1-v)(1-2 v)}{R_{4}\left(R_{4}+z+\tau\right)^{2}}\left(3-\frac{S^{2}\left(3 R_{4}+z+\tau\right)}{R_{4}^{2}\left(R_{4}+z+\tau\right)}\right) \\
& \left.-\frac{6 \tau}{R_{4}^{5}}\left(3 \tau-(3-2 v)(z+\tau)+\frac{5 x S^{2}}{R_{4}^{2}}\right)\right],
\end{aligned}
$$$$
\mathrm{R}_{3}=\sqrt{(x-\xi)^{2}+(y-\eta)^{2}+(z-\tau)^{2}},
$$$$
\mathrm{R}_{4}=\sqrt{(x-\xi)^{2}+(y-\eta)^{2}+(z+\tau)^{2}},
$$

where $\gamma=$ unit weight of soil $\left(\mathrm{kN} / \mathrm{m}^{3}\right), d=$ excavation depth (m), $\quad v=$ Poisson's ratio, $\quad K_{0}=$ coefficient of lateral earth pressure at rest $\left(K_{0}=1-\sin \varphi\right.$, where $\varphi$ is the angle of internal friction of soil), $S=$ distance between the vertical side of the excavation and the axis of the constructed tunnel (m), and $\tau=$ depth of the calculation point on the vertical side of the excavation $(\mathrm{m})$.
By integrating Equations (6) and (7) over the excavation bottom and integrating Equations (9) and (10) over the vertical side of the excavation, the excavation unloadinginduced additional stress corresponding to the excavation bottom and to the vertical side of the excavation can be derived, respectively. In this case, the total vertical and horizontal additional stresses in the constructed tunnel induced by excavation with dewatering, $\sigma^{v}$ and $\sigma^{h}$, have the forms

$$
\begin{gathered}
\sigma^{v}=\sigma_{w}^{v}+\sigma_{d}^{v}+\sigma_{c}^{v}, \\
\sigma^{h}=\sigma_{d}^{h}+\sigma_{c}^{h} .
\end{gathered}
$$

\section{Response of Constructed Tunnel}

The internal force and displacement characteristics for the constructed tunnel under the effect of the additional stress induced by the adjacent excavation with dewatering are predicted in this section based on the beam on elastic foundation theory. To achieve this, it is assumed that (1) the constructed tunnel is equivalent to a long beam on an elastic foundation, (2) the contact between the constructed tunnel and the ground is perfect, and (3) compatibility of deformation is satisfied. A schematic of the calculation model for the response of the constructed tunnel under the additional stress is presented in Figure 3.

According to the Winkler foundation beam model, the equation of deflection curve for the constructed tunnel under the effect of the additional stress has the form

$$
E I_{\mathrm{eq}} \frac{d^{4} w(x)}{d x^{4}}+D k w(x)=p(x)
$$

where $E I_{\mathrm{eq}}=$ equivalent longitudinal stiffness of the constructed tunnel $\left(\mathrm{kN} \cdot \mathrm{m}^{2}\right), w(x)=$ displacement of the constructed tunnel $(\mathrm{m}), D=$ external diameter of the constructed tunnel $(\mathrm{m}), k=$ coefficient of subgrade reaction $\left(\mathrm{kN} \cdot \mathrm{m}^{3}\right)$, and $p(x)=$ additional stress applied on the constructed tunnel $(\mathrm{kPa})$.

In Equation (13), $p(x)$ and $E I_{\mathrm{eq}}$ are given by

$$
\begin{aligned}
& p(x)=\sigma D, \\
& E I_{\mathrm{eq}}=\eta E I,
\end{aligned}
$$

where $\eta=$ reduction coefficient and $E I=$ actual longitudinal stiffness of the constructed tunnel $\left(\mathrm{kN} \cdot \mathrm{m}^{2}\right)$.

The magnitude of the reduction coefficient $\eta$ varies, depending on many factors such as the form of tunnel circumferential seam, bolt quantity, and tunnel lining thickness [44-46]. By performing a series of experiments, Xu [47] investigated the magnitude of the reduction coefficient $\eta$ at various forms of tunnel circumferential seam. It was found that the magnitudes of the reduction coefficient $\eta$ are, respectively, $0.145,0.13$, and 0.114 at homogeneous, staggered, and continuous forms of the tunnel circumferential seam.

A previous experimental study has indicated that the coefficient of subgrade reaction $k$ is related to not only the soil strength but also the stiffness of the foundation beam 


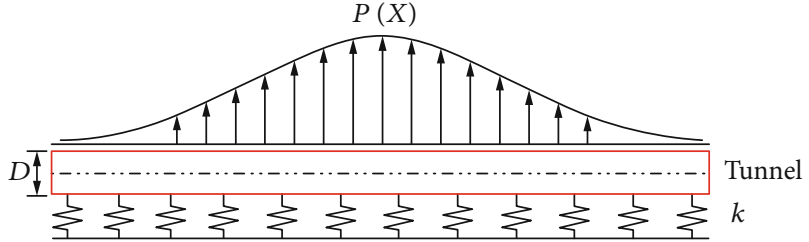

FIGURE 3: Schematic of calculation model for tunnel response under the additional stress.

$[48,49]$. Therefore, the empirical equation proposed by Vesic [50] and Attewell et al. [51] was adopted to estimate the coefficient of subgrade reaction $k$ :

$$
k=2 k_{\mathrm{Vesic}}=\frac{1.3 E_{s}}{D\left(1-v^{2}\right)} \sqrt[12]{\frac{E_{s} D^{4}}{E I_{\text {eq }}}},
$$

where $E_{s}=$ elastic modulus of the ground (MPa).

As Equation (13) is an inhomogeneous differential equation of fourth order with a constant coefficient, it is extremely difficult to derive directly its analytical solution. Therefore, the form of the analytical solution was assumed to be composed of two parts: the general solution part and the particular solution part. Let $p(x)=0$, one can obtain the corresponding homogeneous differential equation

$$
E I_{\mathrm{eq}} \frac{d^{4} w(x)}{d x^{4}}+D k w(x)=0 .
$$

Therefore, the general solution has the form

$$
\begin{aligned}
w(x)= & e^{\lambda x}\left(C_{1} \cos (\lambda x)+C_{2} \sin (\lambda x)\right) \\
& +e^{-\lambda x}\left(C_{3} \cos (\lambda x)+C_{4} \sin (\lambda x)\right), \\
\lambda= & \sqrt[4]{\frac{D K}{4 E I_{\mathrm{eq}}}}
\end{aligned}
$$

where $C_{1}, C_{2}, C_{3}$, and $C_{4}=$ undetermined coefficients and $\lambda$ $=$ elastic characteristic coefficient.

Considering the symmetry of the beam on an elastic foundation, we have

$$
\begin{array}{r}
\left.w(x)\right|_{x \rightarrow \infty}=0, \\
\left.\frac{d w(x)}{d x}\right|_{x \rightarrow \infty}=0 .
\end{array}
$$

By manipulation of Equations (17) and (18), one obtains $C_{1}=C_{2}=0$ and $C_{3}=C_{4}$. Let $C_{3}=C_{4}=C$, the form of the general solution for Equation (16) can be transformed to

$$
w(x)=C e^{-\lambda x}(\cos (\lambda x)+\sin (\lambda x)) .
$$

Assume that a point load $P_{0}$ is applied at the central section of the beam on an elastic foundation. Considering the equilibrium between the subgrade reaction and the external load, we have

$$
2 D k C \int_{0}^{\infty} e^{-\lambda x}(\cos (\lambda x)+\sin (\lambda x)) d x=P_{0} .
$$

Manipulation of Equation (20) leads to

$$
C=\frac{P_{0} \lambda}{2 D k}
$$

Substituting Equation (21) into Equation (19), the form of the general solution becomes

$$
w(x)=\frac{P_{0} \lambda}{2 D k} e^{-\lambda x}(\cos (\lambda x)+\sin (\lambda x))
$$

For a tunnel subjected to an additional distributed load $q(x)$, the point load at the point $\xi$ on the tunnel is $q(\xi) d \xi$. Under this point load, the induced displacement at the point $x$ on the tunnel, $d w(x)$, is calculated, according to Equation (22), as

$$
d w(x)=\frac{P(\xi) \lambda}{2 D k} e^{-\lambda|x-\xi|}(\cos (\lambda|x-\xi|)+\sin (\lambda|x-\xi|)) d \xi .
$$

Integrating Equation (23) over the range of the distribution of the additional distributed load, the solution for Equation (13) is derived:

$w(x)=\frac{\lambda}{2 D k} \int_{-\infty}^{+\infty} P(\xi) e^{-\lambda|x-\xi|}(\cos (\lambda|x-\xi|)+\sin (\lambda|x-\xi|)) d \xi$

Consequently, the bending moment and shear force at the point $x$ on the tunnel axis are calculated, respectively, by

$$
\begin{gathered}
M=-E I_{\mathrm{eq}} \frac{d^{2} w(x)}{d x^{2}}, \\
Q=\frac{d M}{d x}=-E I_{\mathrm{eq}} \frac{d^{3} w(x)}{d x^{3}} .
\end{gathered}
$$

The proposed method for predicting the response of a constructed tunnel to an adjacent excavation with dewatering treats the constructed tunnel as a long beam on an elastic foundation and calculates the internal force and deformation for the constructed tunnel by using the Winkler foundation model. The required parameters for the proposed method include the equivalent longitudinal stiffness of the constructed tunnel $E I_{\text {eq }}$, external diameter of the constructed tunnel $D$, and coefficient of subgrade reaction $k$. The advantages of the proposed method over other models are lesser parameters and convenient calculation process. 


\section{Verification}

The performance of the proposed theoretical method for predicting the deformation and internal force characteristics of a constructed tunnel induced by an adjacent excavation with dewatering is challenged against three well-documented case histories. The predicted tunnel displacement characteristics are verified by the comparisons with the monitoring data obtained in the field and the three-dimensional finite element analysis results obtained in this study. The ability of the proposed method in well predicting the tunnel internal force characteristics is demonstrated by comparing it with the three-dimensional finite element analysis results.

4.1. Shanghai Dongfang Road Interchange Project. The first case history used for verifying the proposed method is the Shanghai Dongfang Road Interchange (SDRI) Project reported in $\mathrm{Xu}$ and Huang [52]. In this case history, the plan view showing the relative position of the excavation and the tunnels is presented in Figure 4. The soil parameters for this case history are listed in Table 2 . The geometry of the excavation resembles a parallelogram of $26 \mathrm{~m}$ in length and $18 \mathrm{~m}$ in width. The short side of the excavation is oriented at $66^{\circ}$ relative to the $x$-axis of the coordinate system. The excavation depth is approximately $6.5 \mathrm{~m}$. The angle between the axis of the constructed tunnels and the $y$-axis of the coordinate system is $45^{\circ}$. The upline of the constructed tunnels is directly below the excavation. The minimum distance between the tunnel crown and the excavation bottom is $2.76 \mathrm{~m}$, with the tunnel cover depth being approximately $9.26 \mathrm{~m}$. The external diameter and the equivalent stiffness of the constructed tunnels are, respectively, $6.2 \mathrm{~m}$ and $3.93 \times 10^{7} \mathrm{kN} \cdot \mathrm{m}^{2}$. In theoretical calculation, it was assumed that the upline of the constructed tunnels was parallel with the excavation, considering the relatively small angle between the upline and the excavation.

In theoretical calculation for this case history, the horizontal additional stress in the upline of the constructed tunnels induced by excavation can be neglected because of the relative position of the upline and the excavation. In other words, the predicted tunnel deformation using the proposed method takes account of only the vertical additional stress induced by excavation.

Figure 5 presents the excavation-induced vertical displacements of the upline tunnel for the SDRI Project obtained by finite element analysis, field measurement, and theoretical calculation. The finite element analysis results presented in Figure 5 were obtained by $\mathrm{Xu}$ and Huang [52] using the MARC software. From Figure 5, it can be indicated that the distribution of the tunnel vertical displacement along the tunnel axis is similar for different methods. The distribution conforms approximately to a Gaussian distribution. The tunnel vertical displacements reach maxima in the middle of the upline tunnel axis intersecting with the vertical projection of the excavation. The maximum tunnel vertical displacements are, respectively, $11.5,16$, and $16.96 \mathrm{~mm}$ corresponding to the finite element analysis, field measurement, and theoretical calculation. The maximum tunnel vertical displacement calculated by the proposed method is more agree-

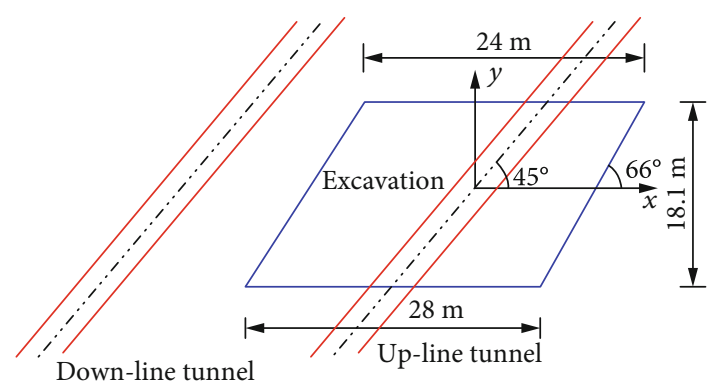

FIgURE 4: Site plan view for the SDRI Project.

TABLE 2: Soil parameters for the SDRI Project [52].

\begin{tabular}{lccccc}
\hline Soil layer & $h(\mathrm{~m})$ & $\gamma\left(\mathrm{kN} / \mathrm{m}^{3}\right)$ & $c(\mathrm{kPa})$ & $\mu$ & $E_{S}(\mathrm{MPa})$ \\
\hline Artificial fill & 1.82 & 18.5 & 16 & NA & NA \\
Silty clay (2) $_{1}$ & 1.13 & 18.4 & 10 & 0.4 & 6.43 \\
Silty clay (2) $_{2}$ & 0.82 & 17.7 & 13 & 0.3 & 3.71 \\
Silty clay (3) $_{1}$ & 1.08 & 17.7 & 14 & 0.3 & 4.43 \\
Sandy silt (3) $_{2}$ & 2.28 & 18.3 & 3 & 0.35 & 9.72 \\
Silty clay (3) $_{3}$ & 2.46 & 17.2 & 13 & 0.35 & 3.63 \\
Sandy silt & 8.7 & 16.6 & 14 & 0.35 & 2.27 \\
Clay (5) & 2.41 & 17.9 & 19 & 0.4 & 4.07 \\
Silty clay (5) & 3.89 & 18.1 & 18 & 0.4 & 4.55 \\
Silty clay & 4.25 & 19.4 & 43 & 0.35 & 6.09 \\
\hline
\end{tabular}

Note. $h=$ soil thickness; $\gamma=$ unit weight; $c=$ cohesion; $\mu=$ Poisson's ratio; $E_{S}$ $=$ modulus of compressibility; $\mathrm{NA}=$ not available.

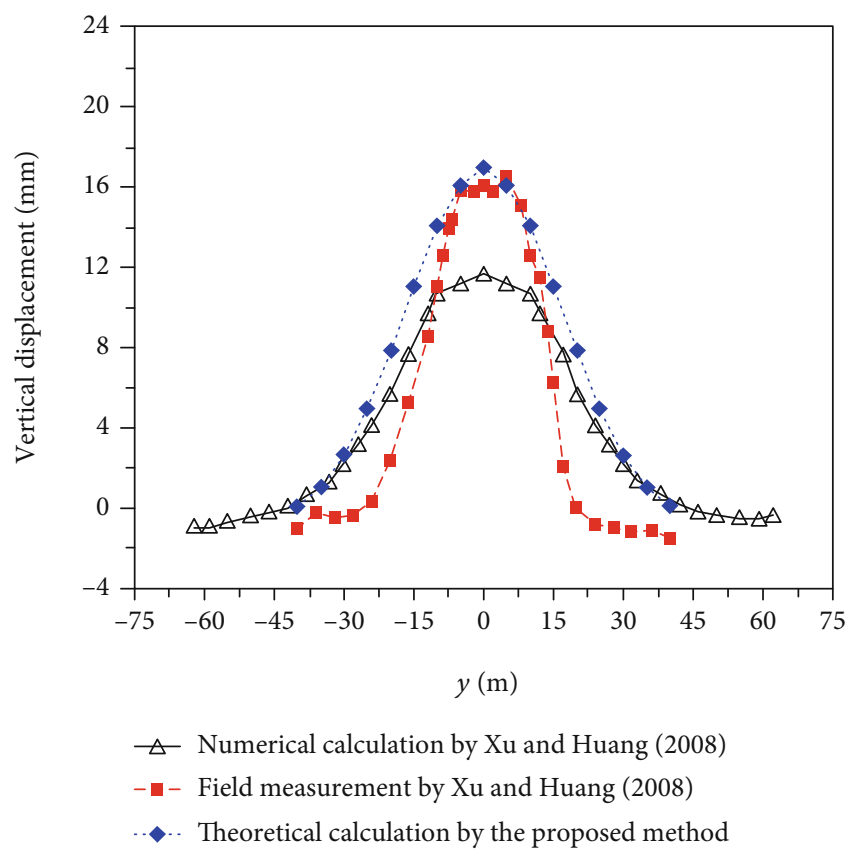

FIGURE 5: Excavation-induced tunnel vertical displacements for the SDRI Project.

able to the field measurement when compared with the finite element analysis result. Moreover, the predicted tunnel vertical displacements by the proposed theoretical method are generally greater than that by finite element analysis and field 


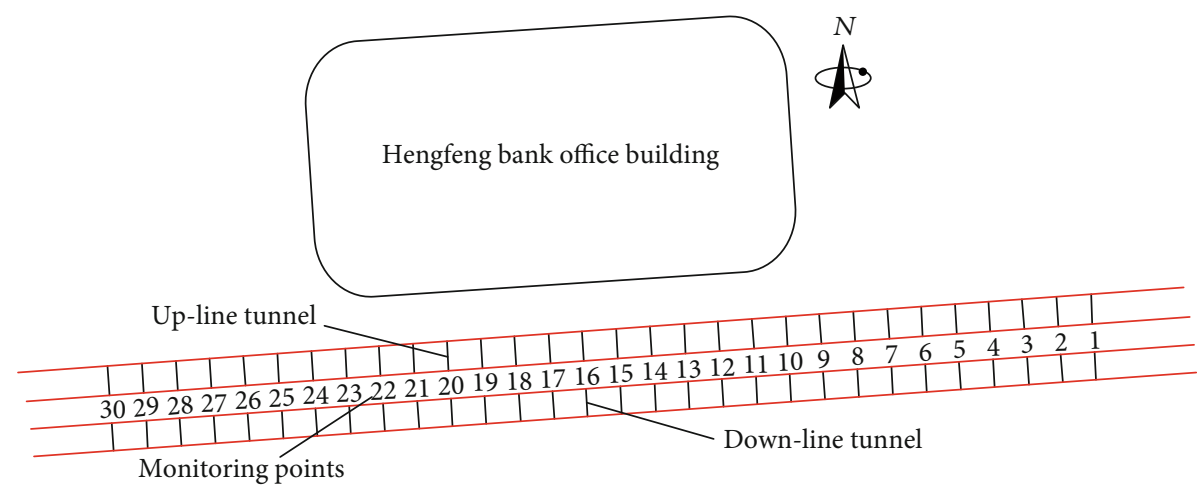

(a)

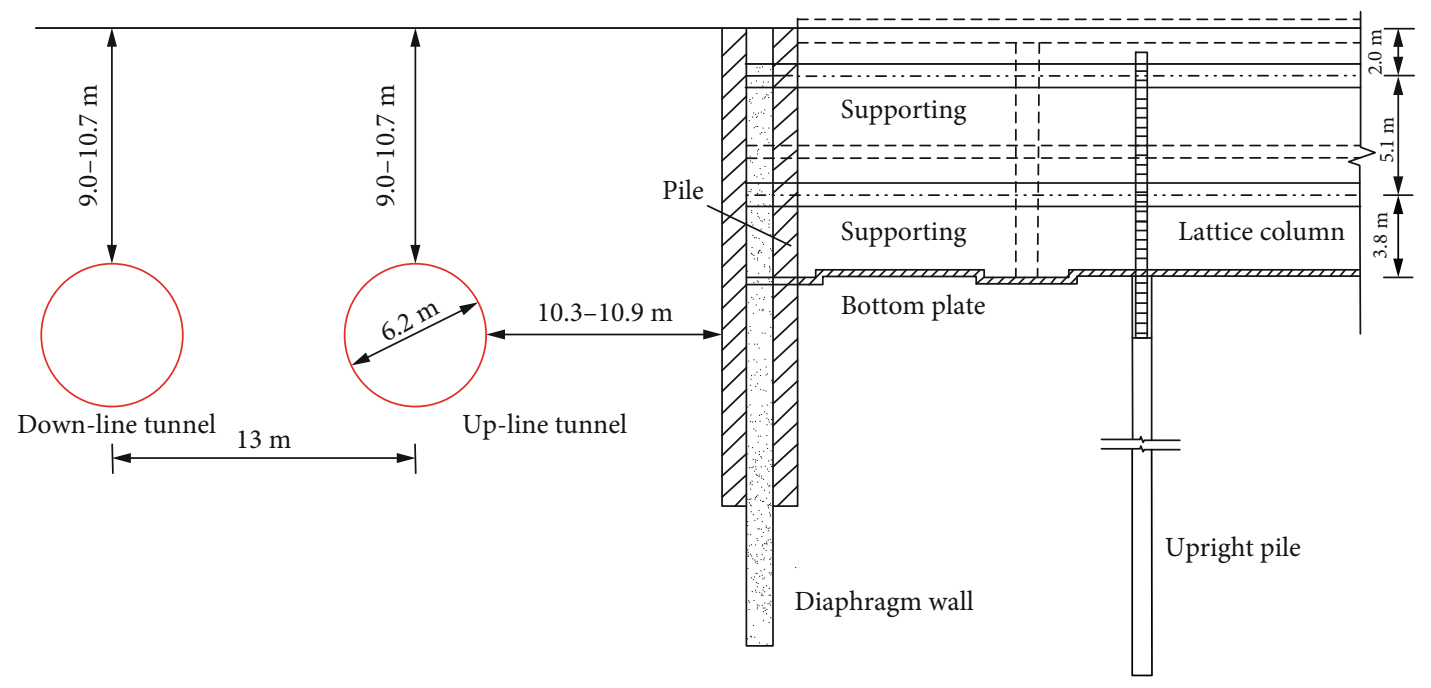

(b)

FIGURE 6: Schematic of the relative position of the excavation and the tunnel for the HBOB Project: (a) plan view and (b) cross-section view.

TABLe 3: Soil parameters for the HBOB Project [53].

\begin{tabular}{lccccc}
\hline Soil layer & $h(\mathrm{~m})$ & $\begin{array}{c}\gamma \\
\left(\mathrm{kN} / \mathrm{m}^{3}\right)\end{array}$ & $\begin{array}{c}c \\
(\mathrm{kPa})\end{array}$ & $\begin{array}{c}E_{S} \\
(\mathrm{MPa})\end{array}$ & $\begin{array}{c}\varphi \\
(\text { degree })\end{array}$ \\
\hline Plain fill (1) & $2.0-4.5$ & 18.9 & 15 & $\mathrm{NA}$ & 10 \\
Powder sticky & $2.5-4.8$ & 19.6 & 32.35 & 6.01 & 13.74 \\
clay (2) & $1.2-4.3$ & 18.8 & 9.84 & 10.76 & 27.83 \\
Silt (3) & $2.1-5.6$ & 18.9 & 17.46 & 6.54 & 13.91 \\
Silty clay (4) 1 & $1.8-3.8$ & 18.7 & 10.86 & 7.6 & 20.29 \\
Silty clay (4) 2 & $5.8-7.0$ & 18.9 & 20.58 & 5.18 & 12.26 \\
Silty clay (4) & $3.1-4.1$ & 20.1 & 60.78 & 7.67 & 13.81 \\
Clay (5) & $6.0-7.2$ & 19.1 & 34.59 & 7.53 & 16.65 \\
Silty clay (6) & $2.0-3.5$ & 18.8 & 20.4 & 6.47 & 13.19 \\
Silty clay (7) & $8.8-9.9$ & 18.7 & 15.36 & 6.97 & 20.24 \\
Silty clay (8) & $5.0-6.9$ & 19.5 & 27.34 & 6.85 & 12.53 \\
Silty clay (9) & $11.5-$ & 19.4 & 23.22 & 7.31 & 14.07 \\
Silty clay (10) & 12.1 & & & & \\
\hline
\end{tabular}

Note. $h=$ soil thickness; $\gamma=$ unit weight; $c=$ cohesion; $E_{S}=$ modulus of compressibility; $\varphi=$ internal friction angle; NA = not available. Poisson's ratio was taken as 0.35 in the calculation for all the soil layers.

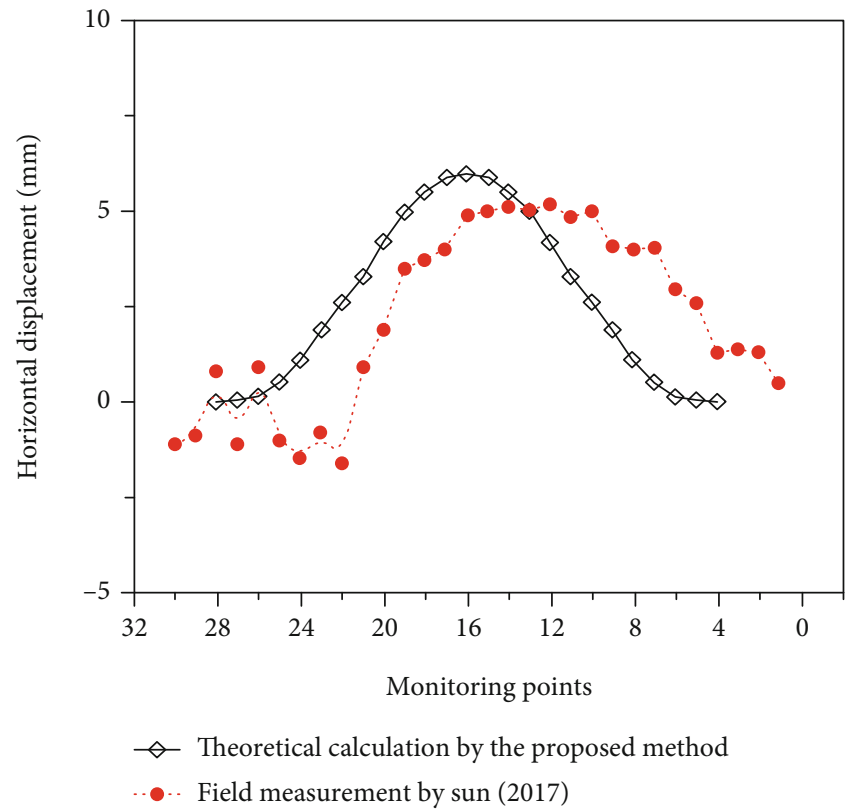

FIgURE 7: Excavation-induced tunnel horizontal displacements for the HBOB Project. 
TABLe 4: Soil parameters for the HMLYRS Project.

\begin{tabular}{|c|c|c|c|c|c|c|c|}
\hline Soil layer & $h(\mathrm{~m})$ & $\gamma\left(\mathrm{KN} / \mathrm{m}^{3}\right)$ & $c(\mathrm{kPa})$ & $\mu$ & $E_{S}(\mathrm{MPa})$ & $\varphi$ (degree) & $k(\mathrm{~m} / \mathrm{d})$ \\
\hline Miscellaneous soil & 5.1 & 17.5 & 8 & 0.35 & NA & 10 & 0.001 \\
\hline Clay $_{1}$ & 4.7 & 19.8 & 10 & 0.3 & 40 & 13 & 0.0006 \\
\hline $\mathrm{Clay}_{2}$ & 6.4 & 20.2 & 15 & 0.29 & 30 & 13 & 0.0004 \\
\hline $\mathrm{Clay}_{3}$ & 6.5 & 20.5 & 25 & 0.26 & 30 & 14 & 0.0004 \\
\hline SWS & 1.1 & 21 & 30 & 0.26 & 70 & 20 & NA \\
\hline Weathered sandstone & NA & 22 & 40 & 0.24 & 90 & 25 & NA \\
\hline
\end{tabular}

Note. $h=$ soil thickness; $\gamma=$ unit weight; $c=$ cohesion; $\mu=$ Poisson's ratio; $E_{S}=$ modulus of compressibility; $\varphi=$ internal friction angle; $k=$ permeability coefficient; NA = not available; SWS = strongly weatherly sandstone.

measurement. For this, the primary reason is that the proposed theoretical method has not taken account of the influence of excavation supporting on the excavation unloadinginduced additional stress.

4.2. Hengfeng Bank Office Building Project. The second case history used for verifying the proposed method is the Hengfeng Bank Office Building (HBOB) Project reported by Sun [53]. In this case history, an excavation adjacent to the Suzhou Metro Line 1 was made for the construction of an office building for Hengfeng Bank. The excavation geometry is approximately a rectangle with its length and width being, respectively, $85 \mathrm{~m}$ and $45 \mathrm{~m}$. The average excavation depth is $10.6 \mathrm{~m}$. To ensure stability and safety, diaphragm walls and concrete structs were used to support the excavation. The relative position of the excavation and the tunnel is depicted in Figure 6. Table 3 summarizes the soil parameters for the HBOB Project.

From Figure 6, it can be seen that the tunnel axis is approximately parallel with the south side of the excavation. The distance between the excavation side and the tunnel periphery ranges from $10.3 \mathrm{~m}$ to $10.9 \mathrm{~m}$. The cover depth of the tunnel ranges from $9.0 \mathrm{~m}$ to $10.7 \mathrm{~m}$. The minimum distance between the upline and downline tunnels is $6.8 \mathrm{~m}$. The external and internal diameters and the equivalent stiffness are, respectively, $6.2 \mathrm{~m}, 5.5 \mathrm{~m}$, and $3.45 \times 10^{7} \mathrm{kN} \cdot \mathrm{m}^{2}$. Monitoring was performed at 30 cross-sections of the upline and downline tunnels with the interval being 5 ring-lengths. For convenience, in theoretical calculation, it was assumed that the tunnels are parallel with the excavation and that the excavation is rectangular in shape.

A comparison of the excavation-induced horizontal displacements of the upline tunnel for the $\mathrm{HBOB}$ Project between the theoretical calculation and field measurement is made in Figure 7. It can be noted that a slight discrepancy exists between the theoretical calculation and field measurement. The maximum tunnel horizontal displacement occurs at a position corresponding to the middle of the excavation, both for the theoretical calculation and field measurement. The maximum tunnel horizontal displacements predicted by the proposed method and monitored by instrumentations are, respectively, $6 \mathrm{~mm}$ and $5.2 \mathrm{~mm}$. The overestimate of the maximum tunnel horizontal displacement by the proposed method is attributed to the overlook of the influence of excavation supporting and stratigraphic distribution.

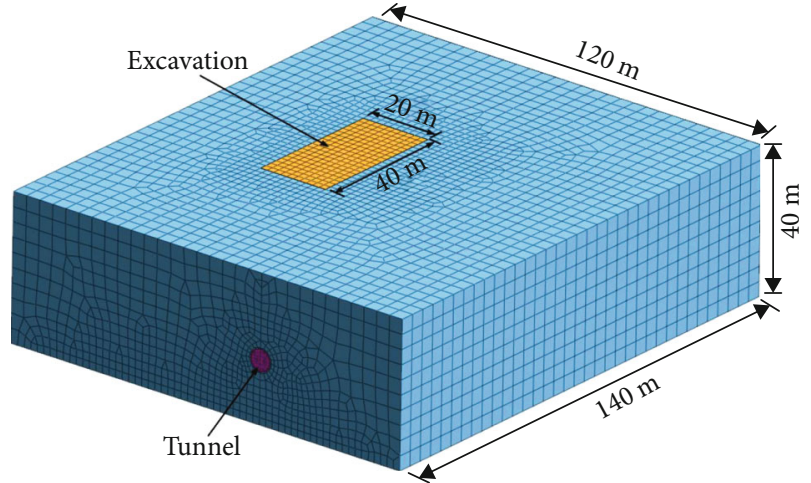

FIGURE 8: Meshing of numerical model for the HMLYRS Project.

4.3. Hefei Metro Line 1 Yungu Road Station Project. The third case history used for verifying the proposed method is the Hefei Metro Line 1 Yungu Road Station (HMLYRS) Project. An imaginary excavation is made adjacent to the HMLYRS Project. By performing three-dimensional finite element analysis, the excavation-induced tunnel internal force and deformation characteristics are compared between the theoretical calculation and numerical analysis results.

According to the drilling data in terms of age of deposition and genetic type as well as the laboratory testing results, the ground stratums for the HMLYRS Project are composed of six layers: miscellaneous fill, clayey soil I, clayey soil II, clayey soil III, highly weathered sandstone, and moderately weathered sandstone. The parameters for these soil layers are summarized in Table 4. The miscellaneous fill consists of construction waste, natural fibers [54-58], and other materials. The groundwater level is about $2.5 \mathrm{~m}$ below the ground surface. The specific yield was taken as 0.1 in the theoretical calculation.

In the three-dimensional finite element analysis, the plan view size of the excavation was assumed to be $40 \mathrm{~m} \times 20 \mathrm{~m}$ $\times 10 \mathrm{~m}$. The water level within the excavation after dewatering was assumed to be $0.5 \mathrm{~m}$ below the excavation bottom. The cover depth of the axis of the constructed tunnels for the HMLYRS Project is $20 \mathrm{~m}$. The distance between the excavation boundary and the tunnel axis is $10 \mathrm{~m}$. The external and internal diameters of the constructed tunnels are, respectively, $6.2 \mathrm{~m}$ and $5.4 \mathrm{~m}$. Taking no account of the influence of the segment joint strength, the equivalent stiffness of the constructed tunnels was taken as $3.45 \times 10^{7} \mathrm{kN} \cdot \mathrm{m}^{2}$. In order to ensure that the numerical analysis results are consistent with 


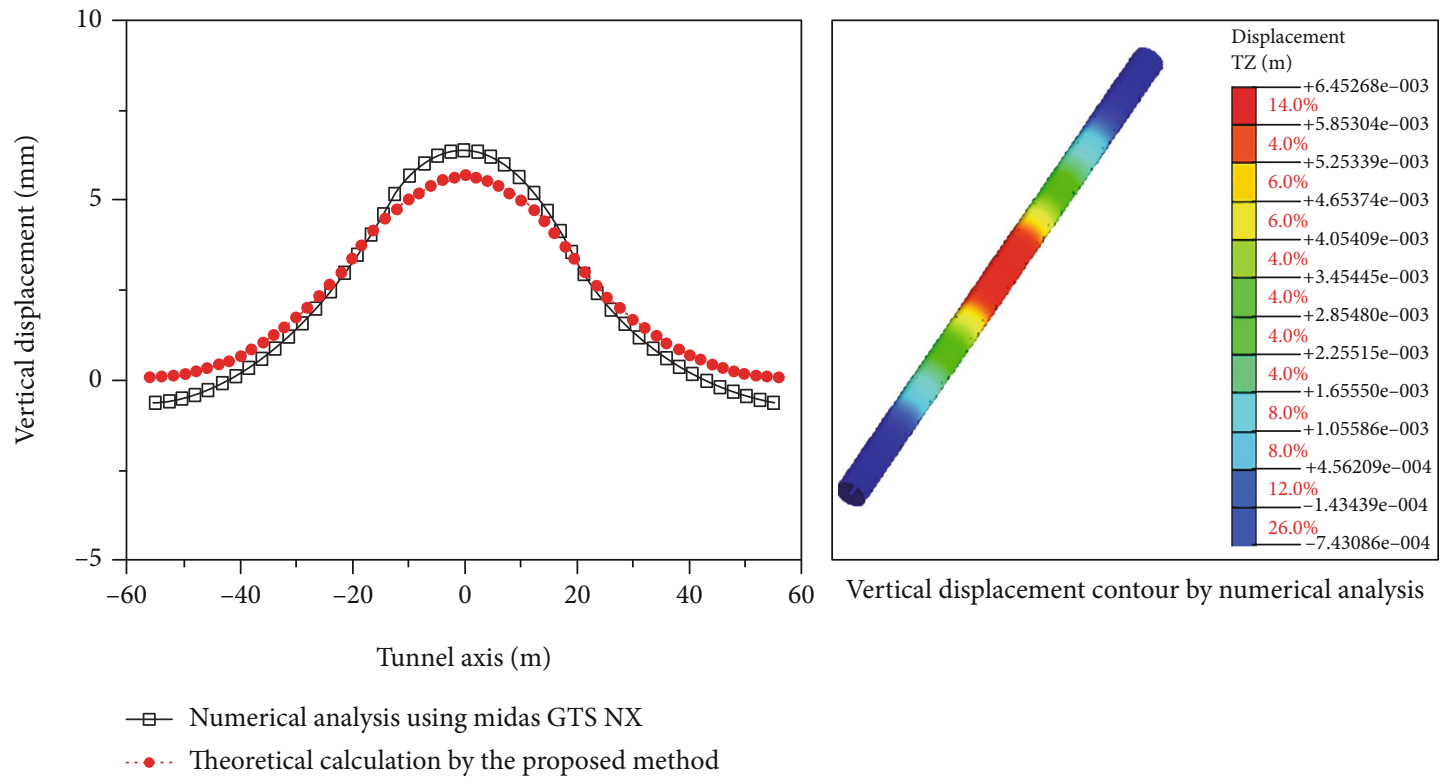

FIgURE 9: Excavation-induced tunnel vertical displacements by numerical and theoretical calculation.

the theoretical calculation results and to mitigate the influence of tunnel dimension on the excavation unloading, the one-dimensional beam element was used to represent the constructed tunnel in numerical modelling. Figure 8 shows the meshing of the numerical model for the HMLYRS Project. It is shown that the dimensions of the numerical model are $120 \mathrm{~m} \times 40 \mathrm{~m} \times 140 \mathrm{~m}$. The Modified Mohr-Coulomb (MMC) model was used to simulate the stress-strain behavior of the soils. In the MMC model adopted by the present numerical analysis, the secant modulus by standard drained triaxial tests was estimated by Equation (27) for the miscellaneous fill and clay (i.e., $E_{50}^{\text {ref }}$ ) and by Equation (28) for the sandstone (i.e., $\tilde{E}_{50}^{\text {ref }}$ ); the unloading/reloading stiffness was estimated by Equation (29) for the miscellaneous fill and clay (i.e., $E_{u r}^{\text {ref }}$ ) and by Equation (30) for the sandstone (i.e., $\tilde{E}_{u r}^{\text {ref }}$ ):

$$
\begin{gathered}
E_{50}^{\mathrm{ref}}=2 E_{\text {oed }}^{\mathrm{ref}}, \\
\tilde{E}_{50}^{\mathrm{ref}}=\tilde{E}_{\text {oed }}^{\mathrm{ref}}, \\
E_{u r}^{\mathrm{ref}}=5 E_{50}^{\mathrm{ref}}, \\
\tilde{E}_{u r}^{\mathrm{ref}}=3 \tilde{E}_{50}^{\mathrm{ref}},
\end{gathered}
$$

where $E_{\text {oed }}^{\text {ref }}=$ tangential stiffness in uniaxial compression tests on miscellaneous fill or clay and $\tilde{E}_{\text {oed }}^{\text {ref }}=$ tangential stiffness in uniaxial compression tests on sandstone.

A comparison of the distribution of excavation-induced tunnel vertical displacement along the tunnel axis is made in Figure 9 between the numerical and theoretical calculation results. It is clear that the two distributions are similar in form. The maximum tunnel vertical displacements are, respectively, $6.45 \mathrm{~mm}$ and $5.70 \mathrm{~mm}$ for the numerical and theoretical calculation results. Moreover, both the magnitude and incidence of the excavation-induced tunnel vertical displacement obtained by numerical analysis are greater than that obtained by theoretical calculation.

Figure 10 compares the distribution of excavationinduced tunnel vertical bending moment along the tunnel axis between numerical and theoretical calculation results. Note that the numerical analysis results in Figure 10 represent the incremental change of the tunnel vertical bending moment before and after the excavation. Clearly, a similar distribution of the excavation-induced tunnel vertical bending moment is found between the numerical analysis and theoretical calculation results. This distribution is almost wshaped and symmetrical with respect to the middle of the tunnel axis. The maximum tunnel vertical bending moments are achieved at the middle of the tunnel axis with the magnitudes being, respectively, $608 \mathrm{kN} \cdot \mathrm{m}$ and $560.31 \mathrm{kN} \cdot \mathrm{m}$ for the theoretical calculation and numerical analysis results. With an increase in the distance between a point on the tunnel axis and the middle of the tunnel axis, the tunnel vertical bending moments decrease gradually both for the theoretical calculation and numerical analysis results. When this distance reaches about $20 \mathrm{~m}$, the tunnel vertical bending moments reverse their direction. The negative tunnel vertical bending moment peaks, respectively, at the distance of about $30 \mathrm{~m}$ with a magnitude of $-272 \mathrm{kN} \cdot \mathrm{m}$ and at the distance of about $27 \mathrm{~m}$ with a magnitude of $-302.83 \mathrm{kN} \cdot \mathrm{m}$ for the theoretical calculation and numerical analysis results. The tunnel vertical bending moments become zero at the ends of the tunnel axis due to the limitation of the excavation depth and length.

Figure 11 presents a comparison of the distribution of excavation-induced tunnel vertical shear force along the tunnel axis between numerical analysis and theoretical calculation results. Note that the numerical analysis results in Figure 11 represent the incremental change of the tunnel vertical shear force before and after the excavation. It can be indicated that the distributions obtained by theoretical 


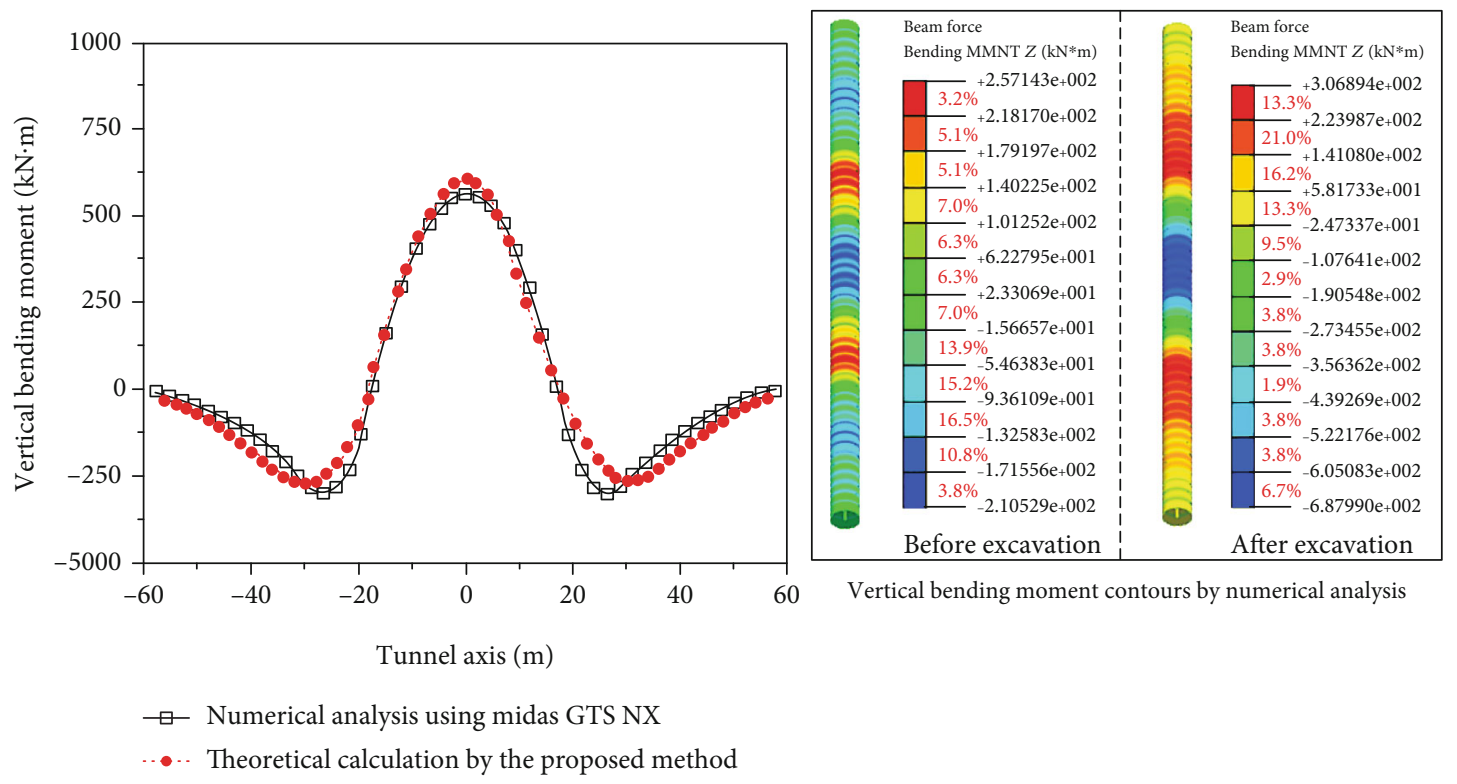

FIGURE 10: Excavation-induced tunnel vertical bending moments by numerical and theoretical calculation.
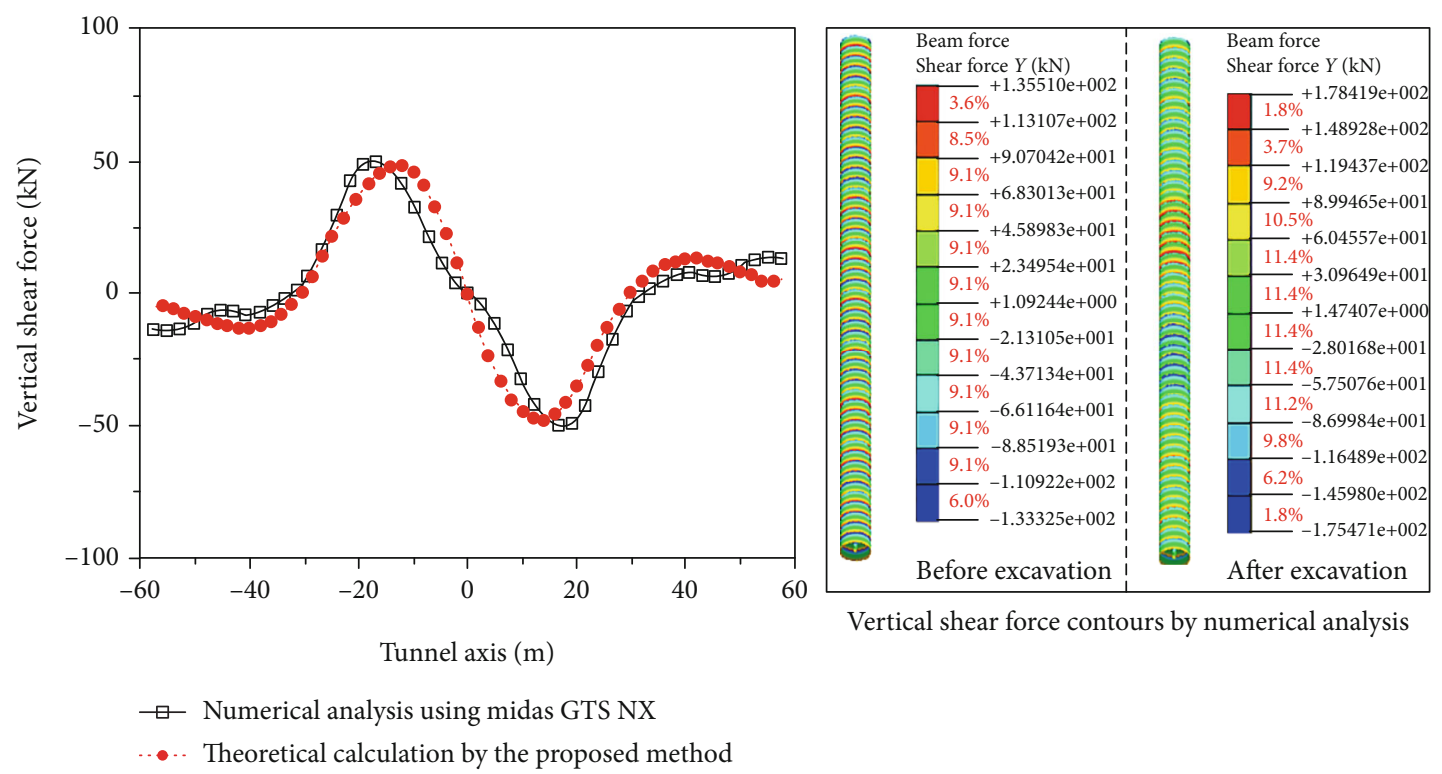

Figure 11: Excavation-induced tunnel vertical shear forces by numerical and theoretical calculation.

calculation and numerical analysis are similar in form. The distributions are nearly antisymmetric about the middle of the tunnel axis. The excavation-induced tunnel vertical shear force is zero in the middle of the tunnel axis and reaches the maximum at a distance of $14 \mathrm{~m}$ from the middle of the tunnel axis for the theoretical calculation result and at a distance of $18 \mathrm{~m}$ for the numerical analysis result. The maxima are, respectively, $48.12 \mathrm{kN}$ and $50.55 \mathrm{kN}$ for the theoretical calculation and numerical analysis results. The shear force stabilizes at a distance of approximately $50 \mathrm{~m}$ from the middle of the tunnel axis.

Based on the three case histories presented above, the performance of the proposed theoretical method in well predicting the excavation-induced internal force and deforma- tion characteristics for a constructed tunnel is validated. Therefore, the proposed theoretical method may serve as a tool to provide a preliminary prediction of the response of a constructed tunnel to an adjacent excavation with dewatering.

\section{Parametric Analysis}

By performing parametric analysis, this section investigates the influence of excavation and tunnel parameters on the vertical displacement and internal force characteristics of a constructed tunnel induced by an adjacent excavation with dewatering. To this end, an imaginary case is considered where the longer side of a rectangular excavation is parallel 


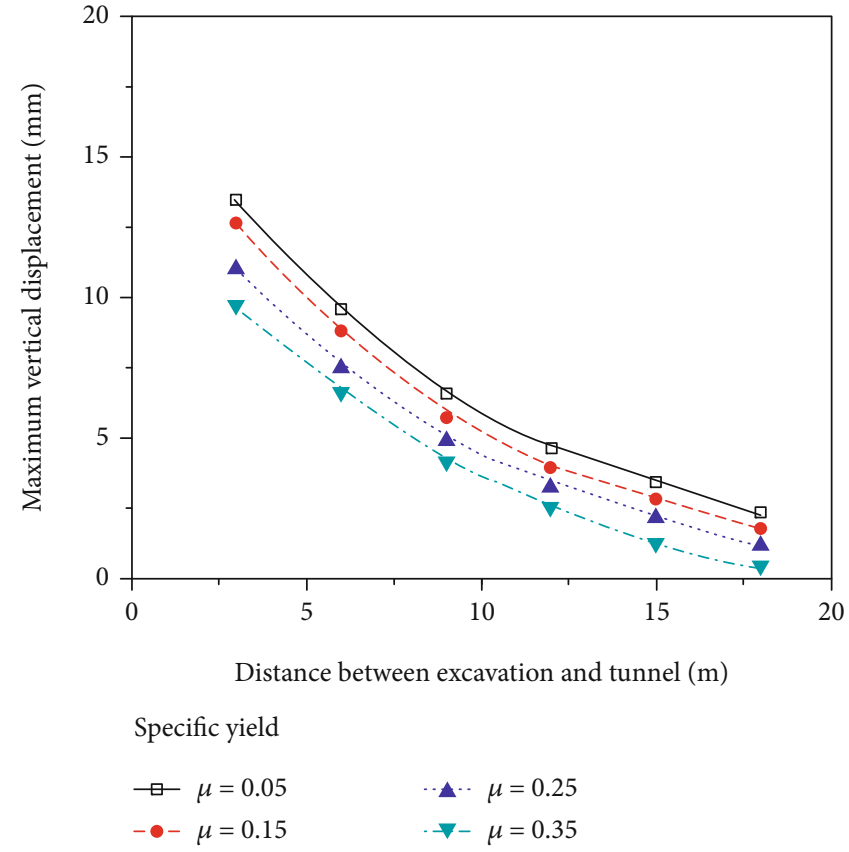

(a)

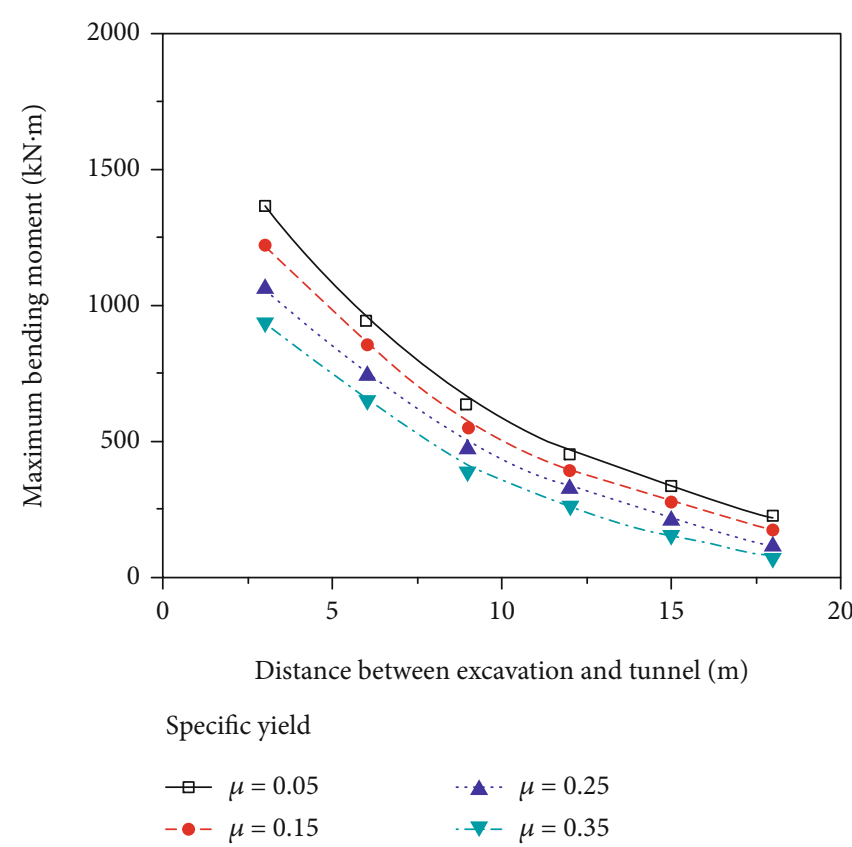

(b)

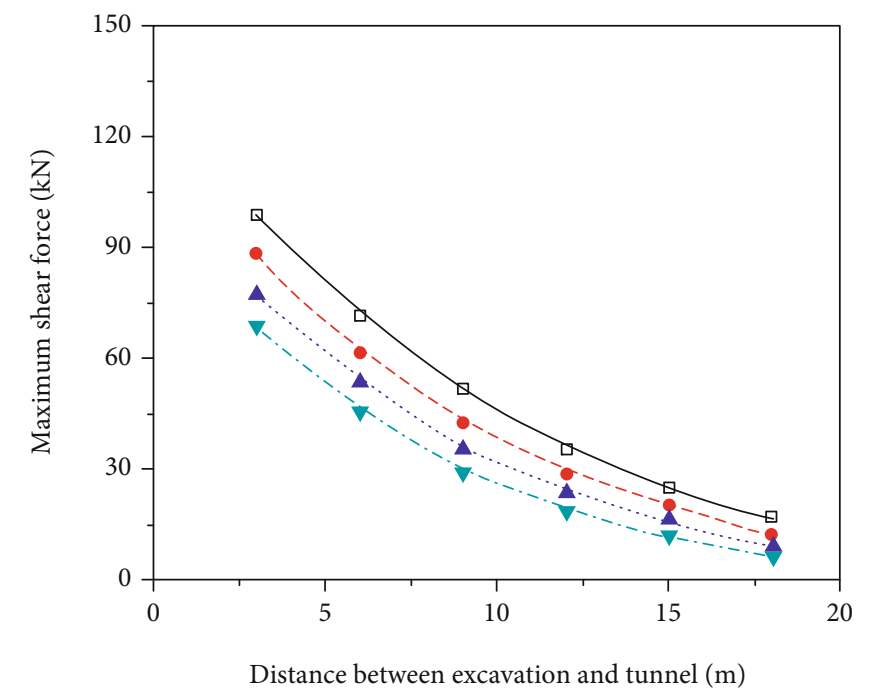

Specific yield

$$
\begin{aligned}
& \rightarrow \mu=0.05 \\
& -\bullet \mu=0.15 \quad-\neg-\mu=0.35
\end{aligned}
$$

(c)

FIGURE 12: Effects of the distance between excavation and tunnel on (a) tunnel maximum vertical displacement; (b) tunnel maximum bending moment; (c) tunnel maximum shear force.

with the axis of the constructed tunnel. For this imaginary case, the soil and tunnel parameters are the same as in the HMLYRS Project described in the former section. In this parametric analysis, the investigated parameters are the distance between excavation and tunnel, initial water level, excavation depth, excavation plan view size, and specific yield.

5.1. Effect of Distance between Excavation and Tunnel. Six different distances are considered between the side of the excavation and the periphery of the constructed tunnel: 3.0, $6.0,9.0,12.0,15.0$, and $18.0 \mathrm{~m}$. Figure 12 presents the effects of the distance between excavation and tunnel on tunnel maximum vertical displacement, tunnel maximum bending moment, and tunnel maximum shear force. It can be indicated from Figure 12 that the tunnel maximum vertical displacement, maximum bending moment, and maximum shear force decrease nonlinearly with an increase in the distance between excavation and tunnel. This decreasing trend 


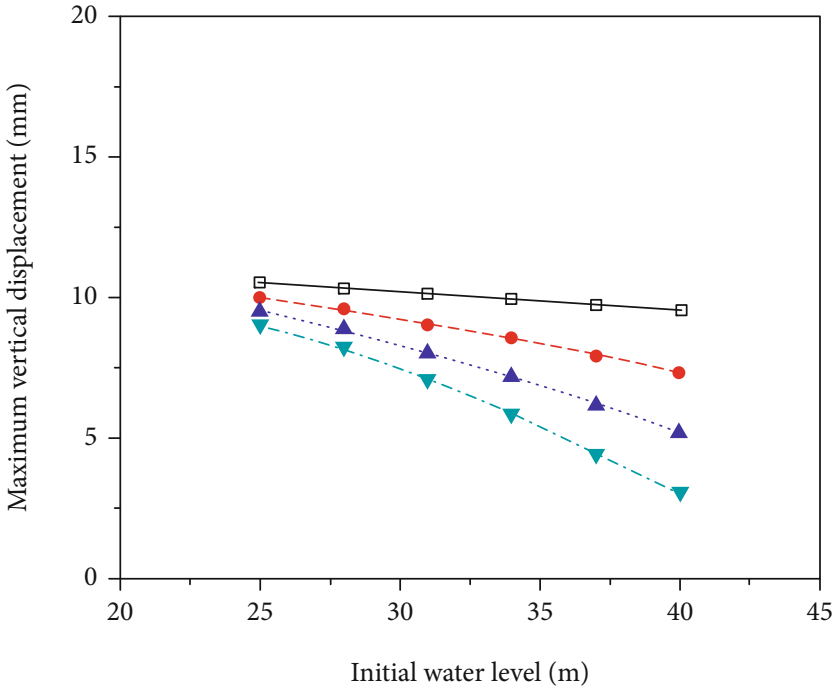

Specific yield

$\rightarrow \mu=0.05$

$-\bullet=0.15$
… $\mu=0.25$

$\nabla-\mu=0.35$

(a)

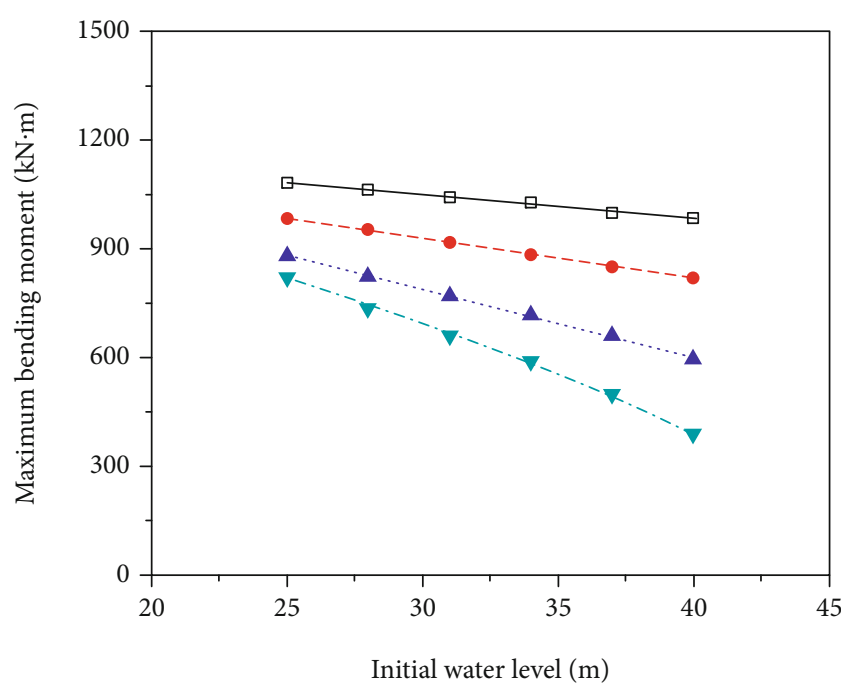

Specific yield

$\longrightarrow \mu=0.05$
$-\bullet \mu=0.15$

... $\mu=0.25$

$\neg-\mu=0.35$

(b)

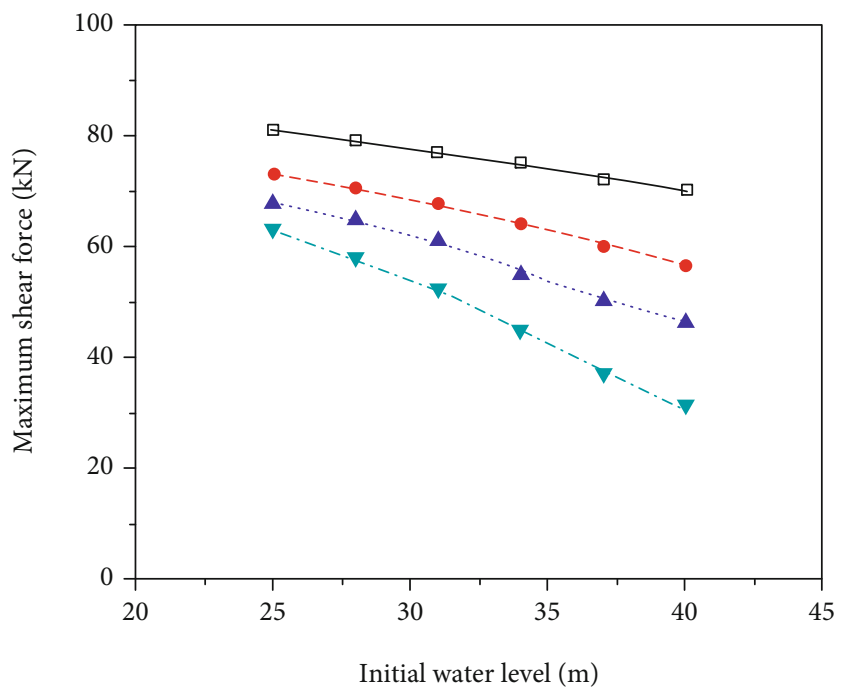

Specific yield

$$
\begin{array}{ll}
\rightarrow \mu=0.05 & \because \cdots \mu=0.25 \\
-\bullet \mu=0.15 & -\checkmark-\mu=0.35
\end{array}
$$

(c)

FIGURE 13: Effects of the initial water level on (a) tunnel maximum vertical displacement; (b) tunnel maximum bending moment; (c) tunnel maximum shear force.

is of a lower rate at a greater distance between excavation and tunnel. At the $18.0 \mathrm{~m}$ distance between excavation and tunnel, the tunnel maximum vertical displacement, maximum bending moment, and maximum shear force are, respectively, $2.2 \mathrm{~mm}, 220.0 \mathrm{kN} \cdot \mathrm{m}$, and $17.5 \mathrm{kN}$. When the distance between excavation and tunnel exceeds $18.0 \mathrm{~m}$, the influence of excavation with dewatering on the responses of the constructed tunnel can be neglected. Moreover, it can also be indicated from Figure 12 that the tunnel maximum vertical displacement, maximum bending moment, and maximum shear force decrease with increasing the specific yield, irrespective of the distance between excavation and tunnel. At the $3.0 \mathrm{~m}$ distance between excavation and tunnel, an increase in the specific yield from 0.05 to 0.35 leads to an approximately $30 \%$ reduction in the tunnel maximum vertical displacement, maximum bending moment, and maximum shear force. This reduction increases to approximately $65 \%$ when the distance between excavation 


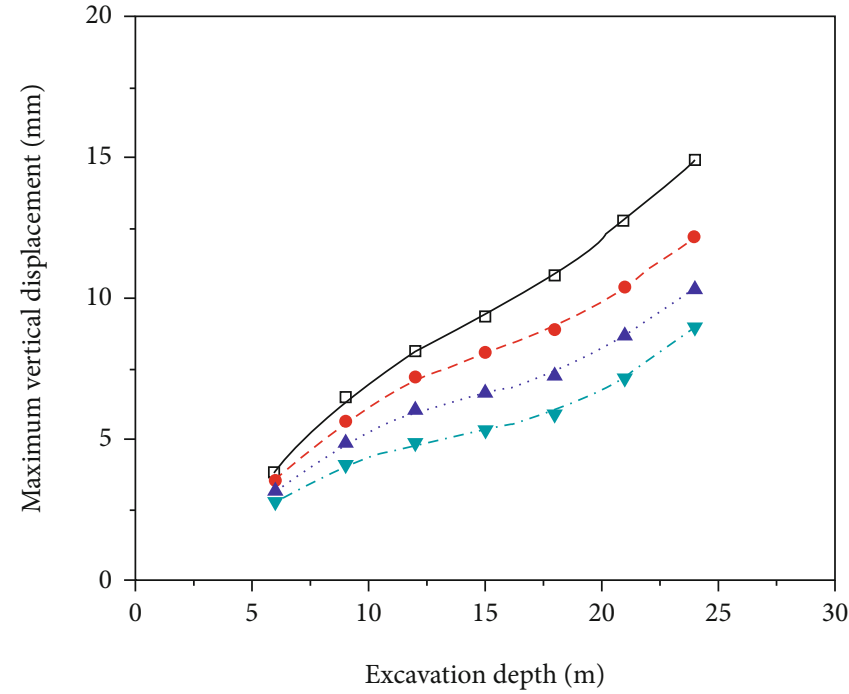

Specific yield

$$
\begin{aligned}
\rightarrow & =0.05 \\
-\bullet & =0.15
\end{aligned}
$$

(a)

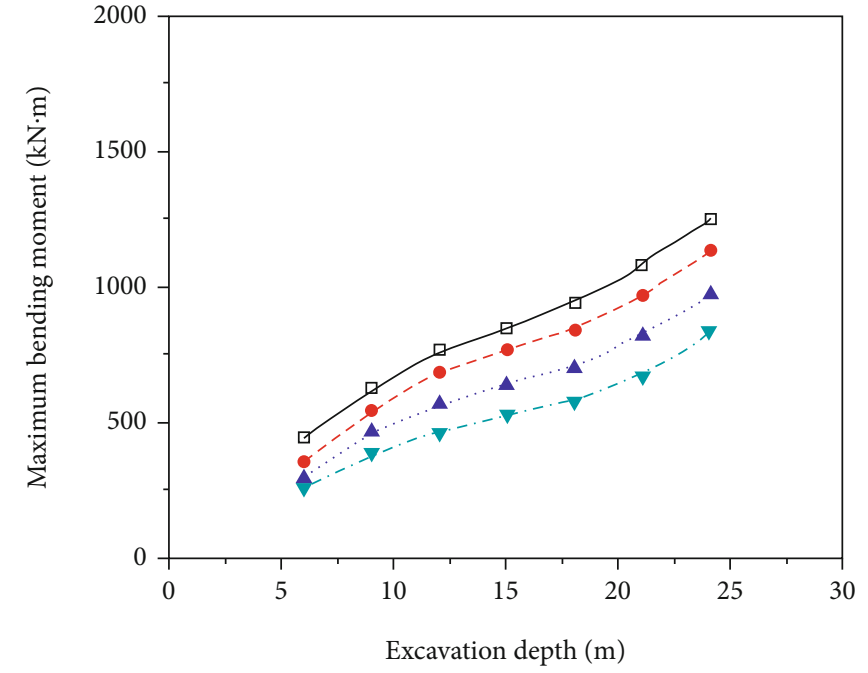

Specific yield

$\rightarrow \quad \mu=0.05$

- - $\mu=0.15$

- $-\mu=0.25$

$\Rightarrow-\mu=0.35$

(b)

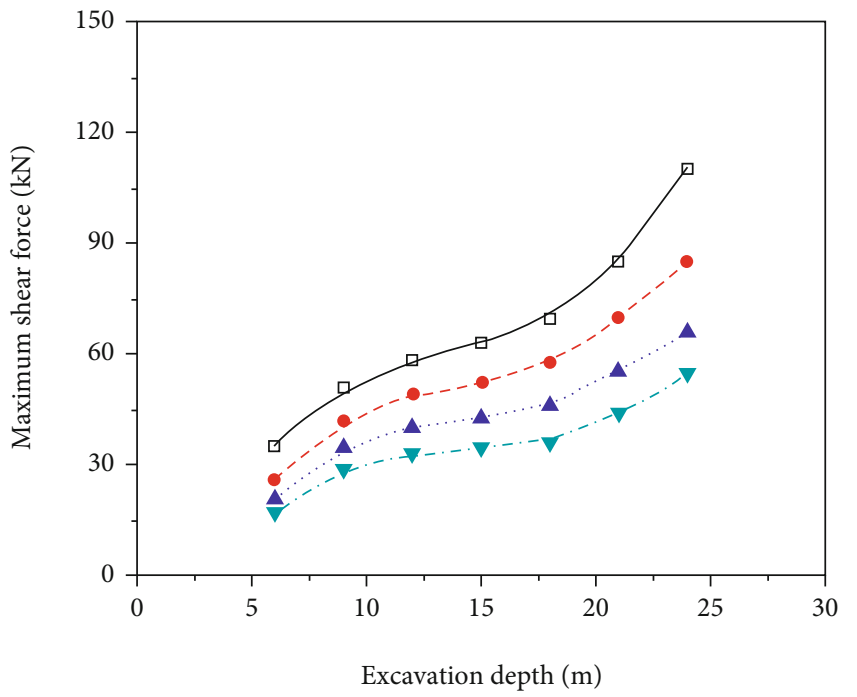

Specific yield

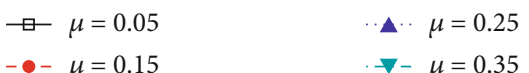

(c)

FIgURE 14: Effects of the excavation depth on (a) tunnel maximum vertical displacement; (b) tunnel maximum bending moment; (c) tunnel maximum shear force.

and tunnel reaches $18.0 \mathrm{~m}$. This indicates that the specific yield has a significant effect on the tunnel maximum vertical displacement, maximum bending moment, and maximum shear force.

5.2. Effect of Initial Water Level. Six different initial water levels are considered in the parametric analysis: 25.0, 28.0, $31.0,34.0,37.0$, and $40.0 \mathrm{~m}$. The effects of the initial water level on the tunnel maximum vertical displacement, maximum bending moment, and maximum shear force are presented in Figure 13. It can be indicated that the tunnel maximum vertical displacement, maximum bending moment, and maximum shear force decrease with an increase in the initial water level. This is attributed to the reduced vertical additional stress on the constructed tunnel at a higher dewatering depth. Moreover, at an initial water 


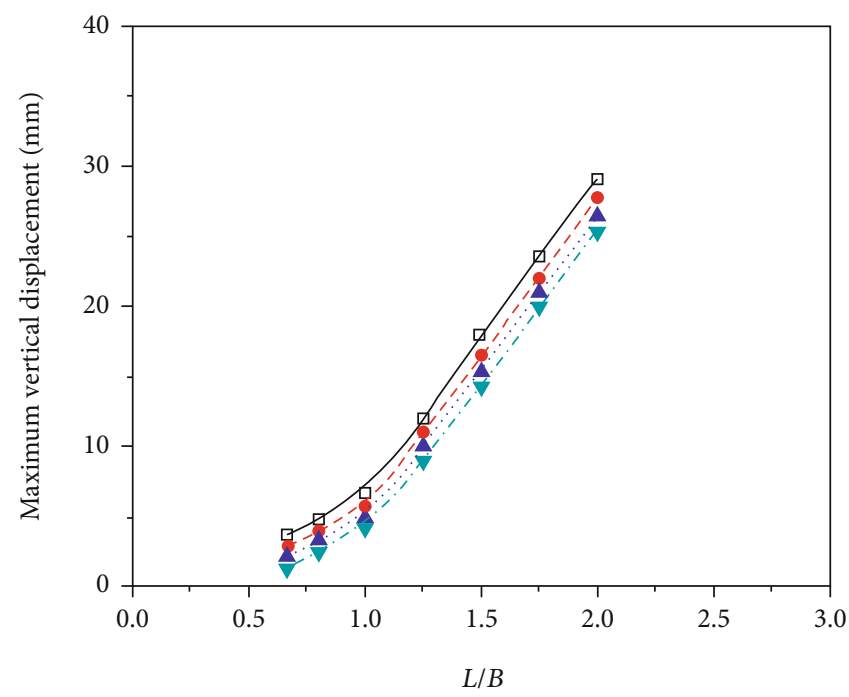

Specific yield

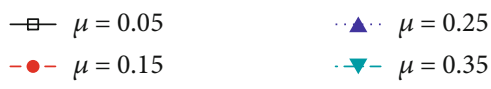

(a)

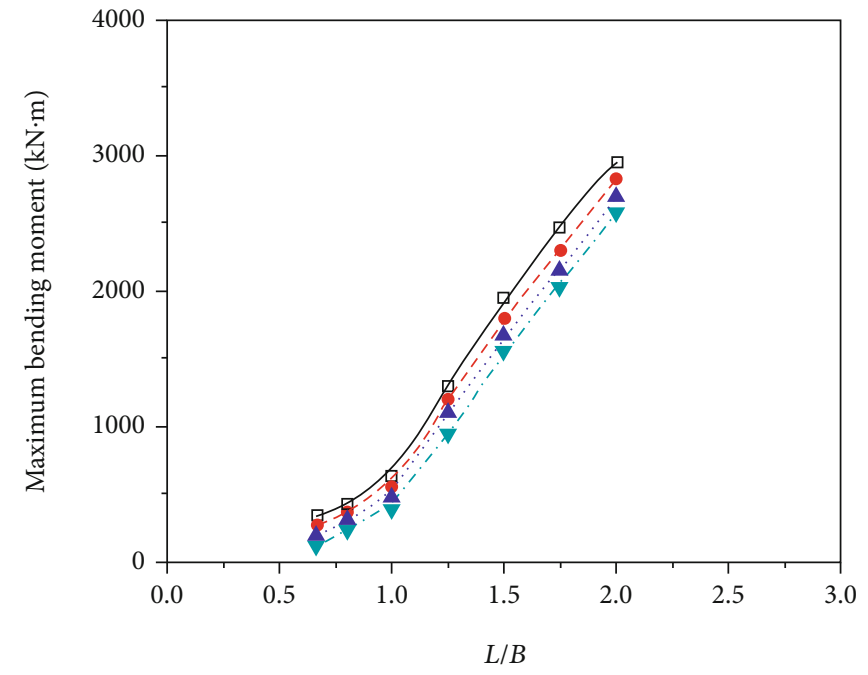

Specific yield

-.. $\mu=0.25$

$\nabla-\mu=0.35$

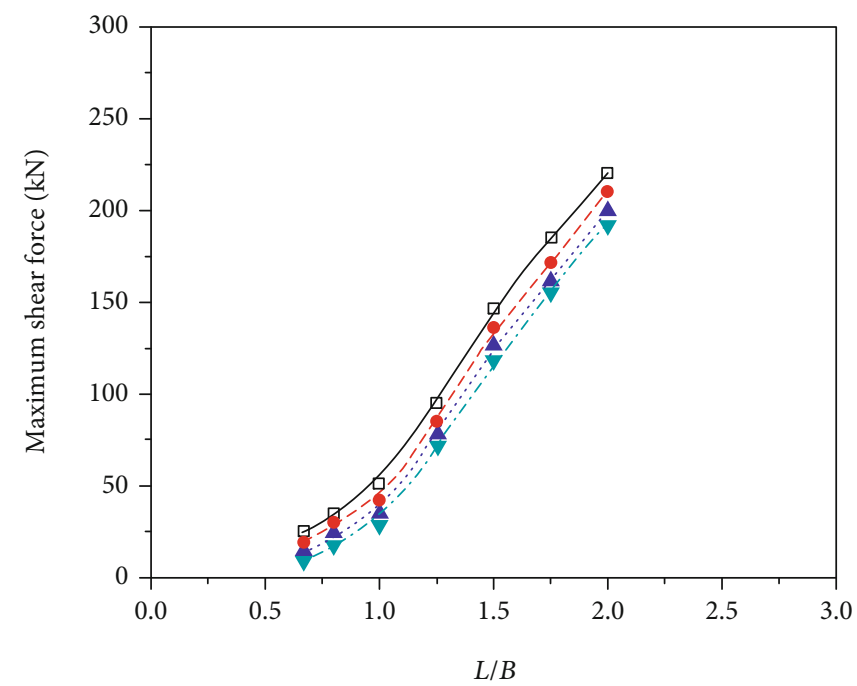

Specific yield

$$
\begin{aligned}
& \square \mu=0.05 \\
& \text { - }-\mu=0.15
\end{aligned}
$$

(c)

FIGURE 15: Effects of the excavation plan view size on (a) tunnel maximum vertical displacement; (b) tunnel maximum bending moment; (c) tunnel maximum shear force.

level, the tunnel maximum vertical displacement, maximum bending moment, and maximum shear force decrease with an increase in the specific yield. The rate of this decrease is higher at a greater initial water level. At the $25.0 \mathrm{~m}$ initial water level, an increase in the specific yield from 0.05 to 0.35 leads to, respectively, $9.6 \%, 24.1 \%$, and $22.2 \%$ reductions in the tunnel maximum vertical displacement, maximum bending moment, and maximum shear force. The reductions are, respectively, $70.0 \%, 60.1 \%$, and $74.0 \%$ at the $40.0 \mathrm{~m}$ initial water level. This indicates that at an excavation depth, the influence of the specific yield on the tunnel displacement and internal force characteristics is more significant at a higher initial water level.

5.3. Effect of Excavation Depth. Seven different excavation depths are considered in the parametric analysis: 6.0, 9.0, $12.0,15.0,18.0,21.0$, and $24.0 \mathrm{~m}$. Figure 14 depicts the effects of excavation depth on the tunnel maximum vertical displacement, maximum bending moment, and maximum shear force. It is shown that the rate of increase in the tunnel 
maximum vertical displacement, maximum bending moment, and maximum shear force as increasing the excavation depth decreases until reaching the $15.0 \mathrm{~m}$ excavation depth and then increases after reaching this excavation depth. At an excavation depth greater than $15.0 \mathrm{~m}$, a striking increase in the tunnel maximum vertical displacement, maximum bending moment, and maximum shear force can be observed with an increase in the excavation depth. This indicates that the effect of excavation depth on tunnel maximum vertical displacement, maximum bending moment, and maximum shear force is more significant at an excavation depth greater than the cover depth of the constructed tunnel. In addition, the tunnel maximum vertical displacement, maximum bending moment, and maximum shear force decrease with increasing the specific yield. At the $6.0 \mathrm{~m}$ excavation depth, an increase in the specific yield from 0.05 to 0.35 causes, respectively, $28.0 \%, 40.8 \%$, and $48.0 \%$ reductions in the tunnel maximum vertical displacement, maximum bending moment, and maximum shear force. The reductions are, respectively, $27.4 \%, 38.0 \%$, and $55.0 \%$ at the 24.0 excavation depth. This indicates that the specific yield has a significant effect on the tunnel maximum vertical displacement, maximum bending moment, and maximum shear force.

5.4. Effect of Excavation Plan View Size. The excavation plan view size is described with the ratio of excavation length to excavation width (i.e., $L / B$ ). In the parametric analysis, seven different excavation plan view sizes are considered: $0.67,0.8$, $1.0,1.25,1.5,1.75$, and 2.0 . The excavation length is fixed at $40.0 \mathrm{~m}$ when $L / B<1.0$; otherwise, the excavation width is fixed at $40.0 \mathrm{~m}$. Figure 15 presents the effects of the excavation plan view size on the tunnel maximum vertical displacement, maximum bending moment, and maximum shear force. It can be indicated that at $L / B<1.0$ or $L / B>1.0$, the tunnel maximum vertical displacement, maximum bending moment, and maximum shear force increase approximately linearly with an increase in $L / B$. Moreover, the rate of increase is greater at $L / B>1.0$ than at $L / B<1.0$, indicating that the effect of changing the excavation width paralleling with the tunnel axis on the tunnel displacement and internal force characteristics is more significant than that for the excavation length perpendicular to the tunnel axis. In addition, with an increase in the specific yield, the tunnel maximum vertical displacement, maximum bending moment, and maximum shear force decrease. At an excavation depth and initial water level, the effect of specific yield on the tunnel displacement and internal force characteristics is not significant for all the considered excavation plan view sizes.

\section{Conclusions}

The safety operation of a constructed tunnel is affected by an adjacent excavation with dewatering. It is significant for practicing engineers to predict the displacement and internal force characteristics of a constructed tunnel induced by an adjacent excavation with dewatering. However, most of the previous theoretical studies relating to this topic focus on the excavation unloading effect and have neglected the effect of dewatering. In view of this, this paper proposes a new method which can account for both the excavation unloading and excavation dewatering effects. The conclusions drawn from this study can be summarized as follows.

(i) The proposed theoretical method taking account of the excavation unloading and dewatering effects is capable of predicting excavation-induced additional stress on the constructed tunnel that agrees well with the actual engineering. By adopting the beam on elastic foundation theory, the tunnel displacement and internal force under the action of the excavation-induced additional stress are derived. This derivation is simple in calculation. The derived results are reliable

(ii) Based on three well-documented case histories, the predicted excavation-induced tunnel displacement and internal force characteristics using the proposed method are compared with the field monitoring and numerical analysis results. The comparison verifies the performance of the proposed method. The proposed method lay the theoretical foundations for the safety assessment and disaster prevention in similar engineering

(iii) A parametric analysis is performed for the effects of excavation depth, distance between excavation and tunnel, excavation plan view size, initial water level, and specific yield on the tunnel displacement and internal force characteristics. It is found that the effect of excavation depth becomes significant when the excavation depth exceeds the cover depth of the constructed tunnel. The influence of adjacent excavation on the constructed tunnel can be overlooked if the distance between excavation and tunnel is greater than the tunnel cover depth. The effect of the excavation plan view size on the side parallel with the tunnel axis is more significant than that on the side perpendicular to the tunnel axis. A higher initial water level corresponds to a smaller excavation-induced additional stress on the constructed tunnel. An increase in the specific yield from 0.05 to 0.35 leads to an approximately $70 \%$ reduction in the tunnel displacement and internal force

\section{Data Availability}

The data used to support the findings of this study are available from the corresponding authors upon request.

\section{Conflicts of Interest}

The authors declare that they have no conflicts of interest.

\section{Acknowledgments}

This paper gets its funding from projects (51774107, 51774322, 51774131, and 51874112) supported by the 
National Natural Science Foundation of China; Project (KFJJ21-03Z) supported by the State Key Laboratory of Explosion Science and Technology, Beijing Institute of Technology, and Project (2018JJ2500) supported by the Hunan Provincial Natural Science Foundation of China; the authors wish to acknowledge these supports.

\section{References}

[1] R. J. Finno and L. S. Bryson, "Response of building adjacent to stiff excavation support system in soft clay," Journal of Performance of Constructed Facilities, vol. 16, no. 1, pp. 10-20, 2002.

[2] Q. Zhang, B. Huang, M. He, and S. Guo, "A numerical investigation on the hydraulic fracturing effect of water inrush during tunnel excavation," Geofluids, vol. 2020, Article ID 6196327, 15 pages, 2020.

[3] B.-C. B. Hsiung, "Geohazard caused by groundwater in urban underground excavation," Geofluids, vol. 2018, Article ID 5820938, 18 pages, 2018.

[4] Y. Wang, Y. Zhang, and G. Wu, "Correlation research of TBM tunnel rock mechanical characteristics, chiseling specific energy, and abrasion performance: case study of Jiaozhou Bay Subsea Tunnel in Qingdao," Geofluids, vol. 2020, Article ID 6658878, 9 pages, 2020.

[5] P. Guo, X. Gong, and Y. Wang, "Displacement and force analyses of braced structure of deep excavation considering unsymmetrical surcharge effect," Computers and Geotechnics, vol. 113, article 103102, p. 17, 2019.

[6] T. Yang, L. Tong, H. Pan, Z. Wang, X. Chen, and H. Li, "Effect of excavation sequence on uplift deformation of underlying existing metro tunnel," Journal of Performance of Constructed Facilities, vol. 35, no. 2, article 04021003, p. 13, 2021.

[7] C. W. W. Ng, M. Shakeel, J. Wei, and S. Lin, "Performance of existing piled raft and pile group due to adjacent multipropped excavation: 3D centrifuge and numerical modeling," Journal of Geotechnical and Geoenvironmental Engineering, vol. 147, no. 4, article 04021012, p. 13, 2021.

[8] X. Shi, C. Rong, H. Cheng, L. Cui, and J. Kong, "An energy solution for predicting buried pipeline response induced by tunneling based on a uniform ground movement model," Mathematical Problems in Engineering, vol. 2020, Article ID 7905750, 12 pages, 2020.

[9] H. L. Liu, P. Li, and J. Y. Liu, "Numerical investigation of underlying tunnel heave during a new tunnel construction," Tunnelling and Underground Space Technology, vol. 26, no. 2, pp. 276-283, 2011.

[10] D. Wu, K. Xu, P. Guo, G. Lei, K. Cheng, and X. Gong, "Ground deformation characteristics induced by mechanized shield twin tunnelling along curved alignments," Advances in Civil Engineering, vol. 2021, Article ID 6640072, 17 pages, 2021.

[11] C. Lin, M. Huang, F. Nadim, and Z. Liu, "Analytical solutions for tunnelling-induced response of two overlying pipelines," Tunnelling and Underground Space Technology, vol. 108, article 103678, p. 14, 2021.

[12] C. Lin, M. Huang, F. Nadim, and Z. Liu, "Tunnelling-induced response of buried pipelines and their effects on ground settlements," Tunnelling and Underground Space Technology, vol. 96, article 103193, p. 17, 2020.

[13] Y. Wang, C. H. Li, and J. Q. Han, "On the effect of stress amplitude on fracture and energy evolution of pre-flawed granite under uniaxial increasing-amplitude fatigue loads," Engineering Fracture Mechanics, vol. 240, article 107366, p. 17, 2020.

[14] X. Z. Liu, Y. L. Sang, F. Zhao, G. Shi, and Y. Heng, "Evaluation of effects of static pile driving on existing metro tunnel structure," Journal of Performance of Constructed Facilities, vol. 33, no. 4, article 04019045, p. 11, 2019.

[15] Y. Wang, W. K. Feng, R. L. Hu, and C. H. Li, "Fracture evolution and energy characteristics during marble failure under triaxial fatigue cyclic and confining pressure unloading (FCCPU) conditions," Rock Mechanics and Rock Engineering, vol. 53, pp. 1-20, 2020.

[16] J. W. Shi, C. W. W. Ng, and Y. H. Chen, "Three-dimensional numerical parametric study of the influence of basement excavation on existing tunnel," Computers and Geotechnics, vol. 63, pp. 146-158, 2015.

[17] J. W. Shi, C. W. W. Ng, and Y. H. Chen, "A simplified method to estimate three-dimensional tunnel responses to basement excavation," Tunnelling and Underground Space Technology, vol. 62, pp. 53-63, 2017.

[18] L. X. Li, J. J. Huang, and B. Han, "Centrifugal investigation of excavation adjacent to existing composite foundation," Journal of Performance of Constructed Facilities, vol. 32, no. 4, article 04018044, p. 12, 2018.

[19] M. G. Li, X. Xiao, J. W. Wang, and J. J. Chen, "Numerical study on responses of an existing metro line to staged deep excavations," Tunnelling and Underground Space Technology, vol. 85, pp. 268-281, 2019.

[20] Y. Wang, S. H. Gao, C. H. Li, and J. Q. Han, "Energy dissipation and damage evolution for dynamic fracture of marble subjected to freeze-thaw and multiple level compressive fatigue loading," International Journal of Fatigue, vol. 142, article 105927, p. 13, 2020.

[21] R. P. Chen, F. Y. Meng, Z. C. Li, Y. H. Ye, and J. N. Ye, "Investigation of response of metro tunnels due to adjacent large excavation and protective measures in soft soils," Tunnelling and Underground Space Technology, vol. 58, pp. 224-235, 2016.

[22] M. Zhu, X. N. Gong, X. Gao, S. M. Liu, and J. J. Yan, "Remediation of damaged shield tunnel using grouting technique: Serviceability improvements and prevention of potential risks," Journal of Performance of Constructed Facilities, vol. 33, no. 6, article 04019062, p. 14, 2019.

[23] X. L. Gan, J. L. Yu, X. N. Gong, and M. Zhu, "Characteristics and countermeasures of tunnel heave due to large-diameter shield tunneling underneath," Journal of Performance of Constructed Facilities, vol. 34, no. 1, article 04019081, p. 13, 2020.

[24] K. H. Chen and F. L. Peng, "An improved method to calculate the vertical earth pressure for deep shield tunnel in Shanghai soil layers," Tunnelling and Underground Space Technology, vol. 75, pp. 43-66, 2018.

[25] G. Zheng, X. Y. Yang, H. Z. Zhou, Y. M. Du, J. Y. Sun, and X. X. Yu, "A simplified prediction method for evaluating tunnel displacement induced by laterally adjacent excavations," Computers and Geotechnics, vol. 95, pp. 119-128, 2018.

[26] H. S. Sun, Y. D. Chen, J. H. Zhang, and T. S. Kuang, “Analytical investigation of tunnel deformation caused by circular foundation pit excavation," Computers and Geotechnics, vol. 201, pp. 193-198, 2019.

[27] M. Huang, C. Zhang, and Z. Li, "A simplified analysis method for the influence of tunneling on grouped piles," Tunnelling and Underground Space Technology, vol. 24, no. 4, pp. 410422, 2009. 
[28] Z. Zhang, M. Zhang, and Q. Zhao, “A simplified analysis for deformation behavior of buried pipelines considering disturbance effects of underground excavation in soft clays," Arabian Journal of Geosciences, vol. 8, no. 10, pp. 7771-7785, 2015.

[29] Z. G. Zhang, M. S. Huang, and W. D. Wang, "Evaluation of deformation response for adjacent tunnels due to soil unloading in excavation engineering," Tunnelling and Underground Space Technology, vol. 38, pp. 244-253, 2013.

[30] R. Z. Liang, T. D. Xia, Y. Hong, and F. Yu, "Effects of abovecrossing tunnelling on the existing shield tunnels," Tunnelling and Underground Space Technology, vol. 58, pp. 159-176, 2016.

[31] R. Z. Liang, T. D. Xia, M. S. Huang, and C. G. Lin, "Simplified analytical method for evaluating the effects of adjacent excavation on shield tunnel considering the shearing effect," Computers and Geotechnics, vol. 58, pp. 224-235, 2017.

[32] J. F. Zhang, J. J. Chen, J. H. Wang, and Y. F. Zhu, "Prediction of tunnel displacement induced by adjacent excavation in soft soil," Tunnelling and Underground Space Technology, vol. 36, pp. 24-33, 2013.

[33] J. W. Shi, Z. Z. Fu, and W. L. Guo, "Investigation of geometric effects on three-dimensional tunnel deformation mechanisms due to basement excavation," Computers and Geotechnics, vol. 106, pp. 106-116, 2019.

[34] R. B. Peck, "Deep excavation and tunneling in soft ground," in Processdings of 7th International Conference on Soil Mechanics and Foundation Engineering, pp. 225-290, Mexico, 1969.

[35] G. T. C. Kung, C. H. Juang, E. C. L. Hsiao, and Y. M. A. Hashash, "Simplified model for wall deflection and groundsurface settlement caused by braced excavation in clays," Journal of Geotechnical and Geoenvironmental Engineering, vol. 133, no. 6, pp. 731-747, 2007.

[36] Y. G. Tang and G. T. C. Kung, "Investigating the effect of soil models on deformations caused by braced excavations through an inverse-analysis technique," Computers and Geotechnics, vol. 37, no. 6, pp. 769-780, 2010.

[37] J. H. Li, L. S. Zhu, and S. J. Zhang, "Numerical calculation of hydrodynamic characteristics of tidal currents for submarine excavation engineering in coastal area," Water Science and Engineering, vol. 9, no. 2, pp. 155-164, 2016.

[38] J. X. Wang, Y. S. Deng, R. Q. Ma et al., "Model test on partial expansion in stratified subsidence during foundation pit dewatering," Journal of Hydrology, vol. 557, pp. 489-508, 2018.

[39] Y. Tan, W. Z. Jiang, W. J. Luo, Y. Lu, and C. J. Xu, "Longitudinal sliding event during excavation of Feng-Qi Station of Hangzhou metro line 1: postfailure investigation," Journal of Performance of Constructed Facilities, vol. 32, no. 4, article 04018039, p. 27, 2018.

[40] T. Ran, F. C. Dai, S. H. Mei, W. W. Wang, and L. H. Tan, "Performance of north anchorage excavation of Fuma Yangtze River Bridge in Wanzhou, China," Journal of Performance of Constructed Facilities, vol. 33, no. 3, article 06019002, p. 11, 2019.

[41] X. F. Ou, X. M. Zhang, X. Q. Liu, J. S. Yang, J. Q. Liu, and X. F. Han, "Analytic calculation method of underlying tunnel deformation caused by excavation and dewatering of upper pit," Journal of the China Railway Society, vol. 41, no. 3, pp. 147154, 2019.

[42] E. I. Anderson, "Modeling groundwater-surface water interactions using the Dupuit approximation," Advances in Water Resources, vol. 28, no. 4, pp. 315-327, 2005.
[43] R. D. Mindlin, "Force at a point in the interior of a semi-infinite solid," Physics, vol. 7, no. 5, pp. 195-202, 1936.

[44] S. M. Liao, F. L. Peng, and S. L. Shen, "Analysis of shearing effect on tunnel induced by load transfer along longitudinal direction," Tunnelling and Underground Space Technology, vol. 23, no. 4, pp. 421-430, 2008.

[45] R. Z. Liang, W. B. Wu, F. Yu, G. S. Jiang, and J. W. Liu, "Simplified method for evaluating shield tunnel deformation due to adjacent excavation," Tunnelling and Underground Space Technology, vol. 71, pp. 94-105, 2018.

[46] J. Y. Han, W. Zhao, P. J. Jia, Y. P. Guang, Y. Chen, and B. F. Jiang, "Risk analysis of the opening of shield-tunnel circumferential joints induced by adjacent deep excavation," Journal of Performance of Constructed Facilities, vol. 32, no. 1, article 04017123, p. 12, 2018.

[47] L. Xu, Study on the Longitudinal Settlement of Shield Tunnel in Soft Soil, Master Thesis, Tongji University, 2005.

[48] G. R. Christian and J. T. Vanmarcke, “Tolerance of buildings to differential settlements," International Journal of Rock Mechanics and Mining Sciences \& Geomechanics Abstracts, vol. 13, no. 11, pp. 137-150, 1976.

[49] Y. C. Kog, C. Kho, and K. K. Loh, "Tunnel design and modulus of subgrade reaction," Journal of Performance of Constructed Facilities, vol. 29, no. 2, article 04014065, p. 8, 2015.

[50] A. S. Vesic, "Bending of beams resting on isotropic elastic solid," Journal of the Engineering Mechanics Division, vol. 87, no. 2, pp. 35-53, 1961.

[51] P. B. Attewell, J. Yeates, and A. R. Selby, Soil Movements Induced by Tunnelling and Their Effects on Pipelines and Structures, Blackie and Son Ltd, London, 1986.

[52] L. Xu and H. W. Huang, "Effect of foundation pit excavation on underlying metro tunnels," Chinese Journal of Geotechnical Engineering, vol. 30, Supplement 1, pp. 164-166, 2008.

[53] B. B. Sun, Effects of Existing Subway Tunnels Due to Adjacent Excavation Construction of Foundation Pit, Master Thesis, Soochow University, 2017.

[54] Y. Wang, P. Guo, F. Dai, X. Li, Y. Zhao, and Y. Liu, "Behavior and modeling of fiber-reinforced clay under triaxial compression by combining the superposition method with the energybased homogenization technique," International Journal of Geomechanics, vol. 18, no. 12, article 04018172, p. 22, 2018.

[55] Y. Wang, P. Guo, H. Lin et al., "Numerical analysis of fiber reinforced soils based on the equivalent additional stress concept," International Journal of Geomechanics, vol. 19, no. 11, article 04019122, p. 17, 2019.

[56] Y.-X. Wang, P.-P. Guo, W.-X. Ren et al., "Laboratory investigation on strength characteristics of expansive soil treated with jute fiber reinforcement," International Journal of Geomechanics, vol. 17, no. 11, article 04017101, p. 12, 2017.

[57] Y. Wang, P. Guo, S. Shan, H. Yuan, and B. Yuan, "Study on strength influence mechanism of fiber-reinforced expansive soil using jute," Geotechnical and Geological Engineering, vol. 34, pp. 1079-1088, 2016.

[58] Y. Wang, P. Guo, X. Li, H. Lin, Y. Liu, and H. Yuan, "Behavior of fiber-reinforced and lime-stabilized clayey soil in triaxial tests," Applied Sciences, vol. 9, no. 5, p. 900, 2019. 